\title{
东亚季风增强加剧中国南部富 $\mathrm{Mg}$ 上地壳化学风化 及其全球意义
}

杨一博 ${ }^{1,2^{*}}$, Albert GALY ${ }^{3}$, 方小敏 ${ }^{1,2,4 \dagger}$, Christian FRANCE-LANORD ${ }^{3}$, 万世明 ${ }^{5,6}$, 杨戎生 ${ }^{1,3,4}, 弓^{\circ}$ 健 $^{1}$, 张胄 ${ }^{7}$, 杨松 $^{8}$, 苗运法 ${ }^{9}$, 刘玉东 ${ }^{1,4}$, 叶程程 ${ }^{1}$

1. 中国科学院青藏高原研究所大陆碰撞与高原隆升重点实验室, 北京 100101 ;

2. 中国科学院青藏高原地球科学卓越创新中心, 北京 100101 ;

3. Centre de Recherches Pétrographiques et Géochimiques, UMR7358, CNRS-Université de Lorraine, Vandoeuvre les Nancy 54500, France;

4. 中国科学院大学, 北京 100049 ;

5. 中国科学院海洋研究所海洋地质与环境重点实验室, 青岛 266071 ;

6. 青岛海洋科学与技术试点国家实验室, 海洋地质过程与环境功能实验室 青岛 266237;

7. 中国科学院大气物理研究所气候变化研究中心, 北京 100029 ;

8. 中国科学院青藏高原研究所环境变化与地表过程重点实验室, 北京 100101 ;

9. 中国科学院西北生态环境资源研究院沙漠与沙漠化重点实验室, 兰州 730000

* 通讯作者, E-mail: yangyibo@itpcas.ac.cn

$\dagger$ 通讯作者, E-mail: fangxm@itpcas.ac.cn

收稿日期: 2020-09-21; 收修改稿日期: 2021-04-06; 接受日期: 2021-05-06; 网络版发表日期: 2021-06-07

第二次青藏高原综合科学考察研究项目(编号：2019QZKK0707)、中国科学院战略性科技先导专项项目(编号：XDA20070201)、国家自然科 学基金项目(批准号：41771236、41972195、41872098、41620104002)、青藏高原地球系统基础科学中心项目(编号：41988101-01)和中国科 学院青年创新促进会项目(编号: 2018095)资助

摘要 渐新世-中新世之交的亚洲气候重组伴随着东亚季风北向推进到中国亚热带地区是一个重要的大气 $\mathrm{CO}_{2}$ 消 耗过程, 但是目前对该过程知之甚少. 本研究近似计算了这次气候重组通过加强中国亚热带地区硅酸盐化学风化 和有机碳埋藏导致的大气 $\mathrm{CO}_{2}$ 消耗。依据侵蚀通量的重建结果，晚渐新世以来硅酸盐风化导致的长期大气 $\mathrm{CO}_{2}$ 消 耗为 $0.06 \times 10^{12} \sim 0.87 \times 10^{12} \mathrm{~mol} \mathrm{a}^{-1}$, 并且其中约 $50 \%$ 的贡献来自于 $\mathrm{Mg}$ 硅酸盐风化. 有机碳埋藏导致的大气 $\mathrm{CO}_{2}$ 消耗 约为同时期硅酸盐风化的 $25 \%$. 本研究强调了中国东部富 $\mathrm{Mg}$ 上部大陆地壳风化对于晚渐新世全球大气 $\mathrm{CO}_{2}$ 含量 下降和新近纪海水 $\mathrm{Mg}$ 含量增加的显著影响. 如果这次气候转型主要与青藏高原隆升有关, 那么本研究揭示了喜 马拉雅-青藏高原的生长通过改变构造欠活跃的东亚地区水循环格局间接调控全球碳和镁循环.

关键词青藏高原, 晚渐新世, 硅酸盐风化, 碳循环, 海洋 $\mathrm{Mg}$ 循环

\footnotetext{
中文引用格式: 杨一博, Galy A, 方小敏, France-Lanord C, 万世明, 杨戎生, 张健, 张再, 杨松, 苗运法, 刘玉东, 叶程程. 2021. 东亚季风增强加剧中国南部富 Mg 上地壳化学风化及其全球意义. 中国科学: 地球科学, 51(8): 1289-1305, doi: 10.1360/N072020-0326

英文引用格式: Yang Y, Galy A, Fang X, France-Lanord C, Wan S, Yang R, Zhang J, Zhang R, Yang S, Miao Y, Liu Y, Ye C. 2021. East Asian monsoon intensification promoted weathering of the magnesium-rich southern China upper crust and its global significance. Science China Earth Sciences, 64 (7):1155-1170, https://doi.org/10.1007/s11430-020-9781-3
} 


\section{1 引言}

硅酸盐风化和有机碳埋藏引起的大气 $\mathrm{CO}_{2}$ 消耗是 地质时间尺度地球调节大气 $\mathrm{CO}_{2}$ 含量的主要机制. 基 于对构造和气候复杂相互作用的认识，科学家们提出 了喜马拉雅-青藏高原隆升主要驱动了新生代大气 $\mathrm{CO}_{2}$ 降低和全球变冷的假说(Raymo等, 1988; Raymo和 Ruddiman, 1992). 该假说认为喜马拉雅-青藏高原隆升 主要通过加强印度-亚洲板块碰撞带的硅酸盐风化(该 观点存在争议, 如Blum等, 1998)和有机碳在南亚孟加 拉扇的有效埋藏(如France-Lanord和Derry，1997)影响 全球地质碳循环。然而，喜马拉雅-青藏高原隆升影响 全球地质碳循环也可以通过强化东亚季风来增加季风 降水, 从而促进东亚地区硅酸盐风化和/或有机碳埋藏 (图1).

现代东亚气候格局从晚渐新世建立以来，干旱区 仅局限在中国西北部，这与晚渐新世之前宽广的干旱 带从西到东横跨中国形成鲜明对比(图1；Sun和Wang， 2005; Guo等, 2008). 东亚季风最近被认为起源于始新 世(如Licht等, 2014), 但是季风活动区域仅局限在中国 最南部(如Guo等, 2008; Spicer等, 2016; Xie等, 2020a, 2020b)．大量化石证据揭示季风深入到现代中国西北 干旱区主要发生在晚渐新世到早中新世(Sun和Wang, 2005; Guo等, 2008; Miao等, 2013; Song等, 2020). 这次 气候重组使得大约 $3.2 \times 10^{6} \mathrm{~km}^{2}$ 的中国亚热带地区从干 旱转变为湿润气候(图1). 如此广阔区域内季风降雨的 增加势必会加速硅酸盐风化和陆源有机质产量. 特别 是中国东部富 $\mathrm{Mg}$ 的扬子和华北克拉通(Gao等，1991, 1998)是这次气候重组涉及的主要地区(图1b). 相对于 $\mathrm{Mg}$ 亏损的喜马拉雅地区岩石(France-Lanord和Derry, 1997)，这些富 Mg上地壳岩石的风化将会显著地消耗 大气 $\mathrm{CO}_{2}$. 为了验证这个假说, 本研究基于中国南海沉 积物和中国东部土壤的化学成分，近似计算了晚渐新 世以来硅酸盐风化和有机碳埋藏过程造成的大气 $\mathrm{CO}_{2}$ 消耗变化.

\section{2 材料和方法}

\section{1 硅酸盐风化消耗 $\mathrm{CO}_{2}$ 的定量方法}

量化硅酸盐风化过程中土壤盐基离子的亏损程 度，可以用盐基离子含量除以风化过程中不活动元素
的含量. 本文使用 $\mathrm{Al}$ 元素作为不活动元素. 其他不活 动元素, 例如 Ti, 可能对风化壳母岩的物源变化比较敏 感(如Ti在中国东部上地壳的铁镁质岩石中富集, Gao 等，1991). 盐基离子 $X$ 在硅酸盐风化中的亏损程度 $\left(\Delta X_{0}, \mathrm{~mol} \mathrm{~kg}^{-1}\right)$ 可表示为

$$
\Delta X_{0}=\left([\mathrm{X}]_{\text {基岩 }}-[\mathrm{Al}]_{\text {基岩 }} /[\mathrm{Al}]_{\text {土壤 }} \times[\mathrm{X}]_{\text {土壤 }} / m_{\mathrm{X}} \times 10,\right.
$$

这里 $[\mathrm{X}]$ 表明元素X在基岩或者土壤中的含量 $(\%), m_{\mathrm{X}}$ 为元素 $\mathrm{X}$ 的摩尔质量.

地质时间尺度 $(>1 \mathrm{Myr})$ 基岩硅酸盐风化导致的 $\mathrm{CO}_{2}$ 消耗 $\left(C_{\mathrm{sil}}, \mathrm{mol} \mathrm{kg}^{-1}\right)$ 可以表示为各主要盐基离子淋 滤程度对应的 $\mathrm{CO}_{2}$ 消耗之和:

$C_{\text {sil }}=\Delta \mathrm{Ca}_{0}+\Delta \mathrm{Mg}_{0}+0.10 \Delta \mathrm{K}_{0}+0.15 \Delta \mathrm{Na}_{0}$,

上式与France-Lanord和Derry(1997)的假设一致：假定 硅酸盐矿物亏损的所有 $\mathrm{Mg}^{2+}$ 和 $\mathrm{Ca}^{2+}$ 最终以海洋碳酸盐 形式沉淀，而仅有 $20 \%$ 的 $\mathrm{K}^{+}$和 $30 \%$ 的 $\mathrm{Na}^{+}$可以最终导致 $\mathrm{CO}_{2}$ 消耗，并且不考虑海洋环境中的反向风化(reverse weathering).

硅酸盐风化引起的 $\mathrm{CO}_{2}$ 消耗 $\left(\Delta_{\mathrm{sil}}\right)$ 可以通过计算气 候重组前后土壤化学成分的差别得到. 因此, 平均土壤 盐基离子在晚渐新世季风加强之前的干旱气候和季风 加强之后湿润气候下的差值可表示为

$$
\begin{aligned}
\Delta_{\text {sil }}= & C_{\text {sil, a }}-C_{\text {sil, }} \\
= & \left(\Delta \mathrm{Ca}_{0, \mathrm{a}}-\Delta \mathrm{Ca}_{0, \mathrm{~b}}\right)+\left(\Delta \mathrm{Mg}_{0, \mathrm{a}}-\Delta \mathrm{Mg}_{0, \mathrm{~b}}\right) \\
& +0.10\left(\Delta \mathrm{K}_{0, \mathrm{a}}-\Delta \mathrm{K}_{0, \mathrm{~b}}\right)+0.15\left(\Delta \mathrm{Na}_{0, \mathrm{a}}-\Delta \mathrm{Na}_{0, \mathrm{~b}}\right) \\
= & \Delta \mathrm{Ca}+\Delta \mathrm{Mg}+0.10 \Delta \mathrm{K}+0.15 \Delta \mathrm{Na},
\end{aligned}
$$

这里下标 $\mathrm{a}$ 和 $\mathrm{b}$ 分别代表季风加强之后和之前的情景.

中国东部大地构造格局，包括华北克拉通、秦岭 造山带、扬子克拉通和华南褶皱系(图1b), 在新生代 之前已经形成, 并且中生代以来一直处于太平洋板块 向西俯冲到欧亚大陆东端引起的地壳拉张构造环境 (图2a; Zheng等, 2013; Fan等, 2019). 因此, 新生代中国 东部暴露于地表的基岩其平均组成总体一致. 并且, 古 近纪中国东部在地壳拉张背景下广泛分布的断陷盆地 (宋博文等, 2020)的沉积速率与青藏高原东北部处于 地壳缩短背景下的盆地沉积速率相当(图2b), 表明古 近纪中国东部构造活动依然活跃. 从风化机制的视角 看, 古近纪中国东部不是一个完全的供应限制(supplylimited)区域(如稳定的地盾/克拉通，那里的风化速率 


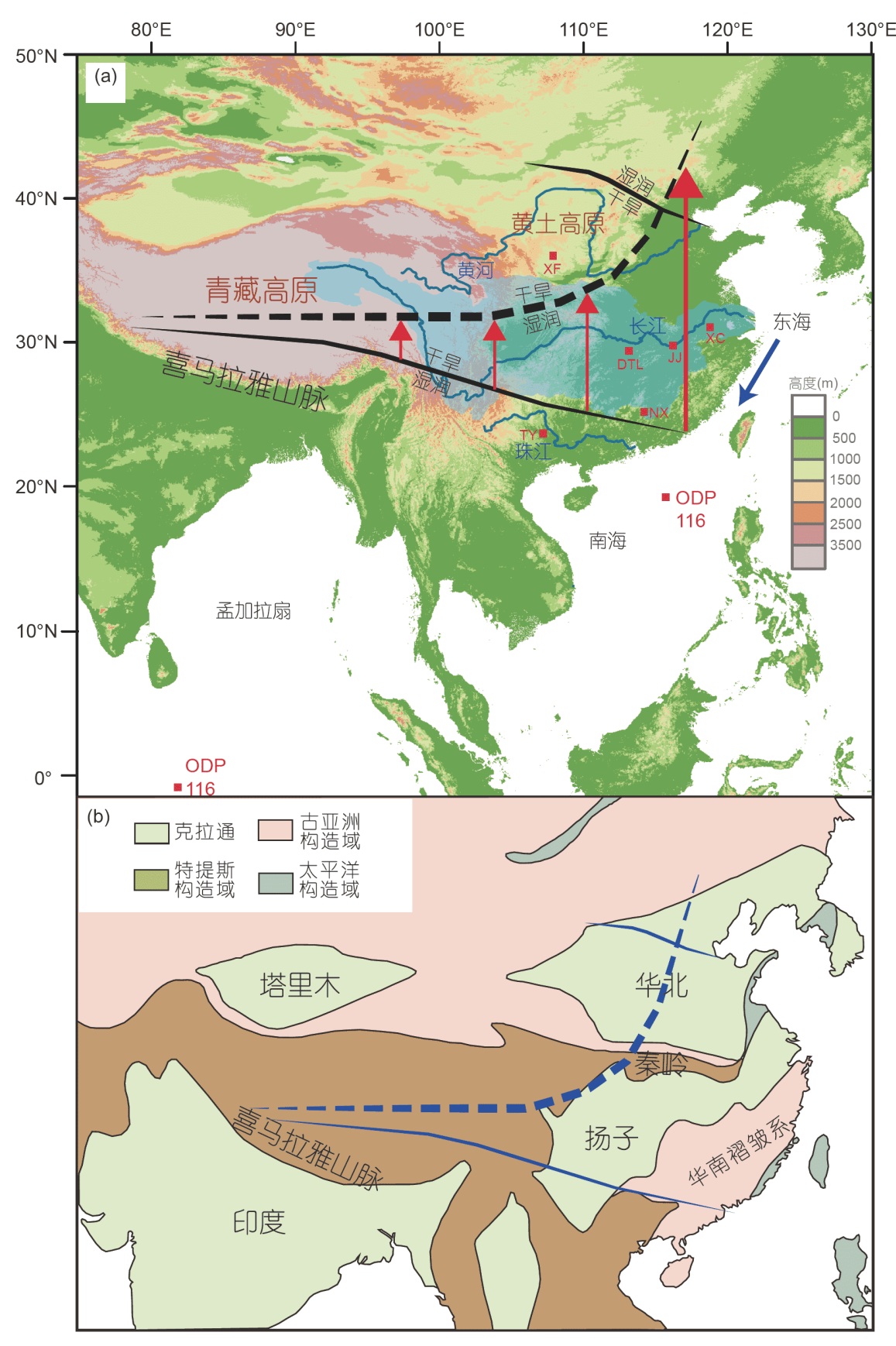

图 1 新生代中国构造和气候格局

(a) 新生代中国干湿界线(古近纪, 黑色粗线; 新近纪到第四纪, 黑色虚线). 红色箭头显示湿润带的北向扩展. 红色方块表示本文采用的数据点 位置(土壤: XF, 西峰; DTL, 洞庭湖, JJ, 九江; XC, 宣城; NX, 南雄; TY, 田阳. 沉积物: 南海ODP1146站, 孟加拉扇ODP116站). 浅蓝色区域表示长 江流域. 蓝色箭头指示沉积物从长江口到南海的现代传输路径(Liu等, 2003). (b) 亚洲大地构造简图显示主要克拉通和造山带的分布(改绘自 Ren等, 2013)

与新鲜矿物供应速率密切相关而对气候变化不敏感, West等, 2005; Maher和Chamberlain, 2014). 珠江流域 约44Ma的剥露速率(图2c)落进了亚高山区域(具有中
等剥露速率的区域，其剥露速率低于以喜马拉雅山为 代表的高山流域, 但高于稳定的地盾/克拉通地区, West等, 2005), 暗示了中国东部仍存在相对较强的气 


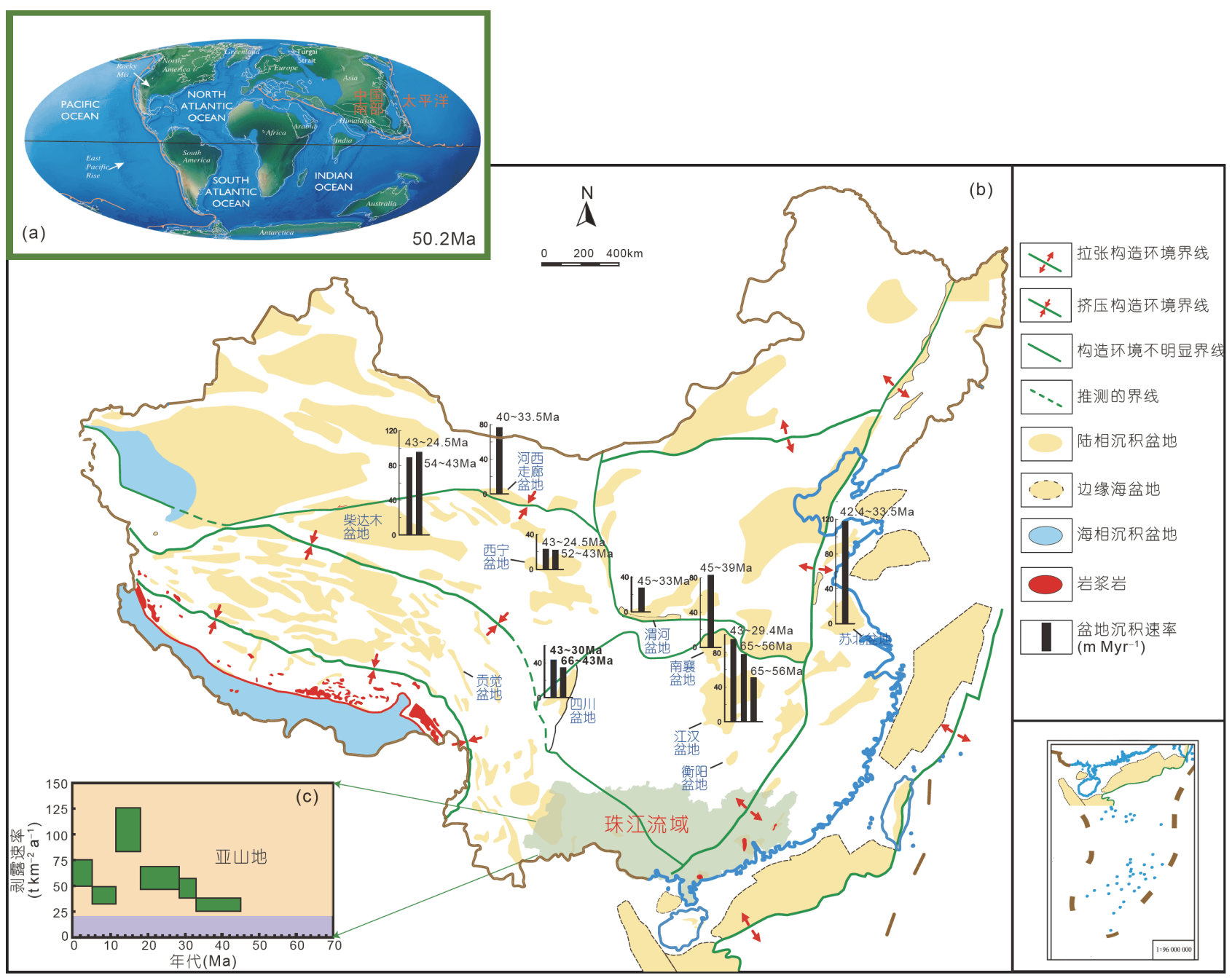

图 2 中国古近纪构造-地层分区

(a) 古近纪古地理图(据Scotese, 2004). (b) 中国古近纪构造-地层分区及盆地分布(改绘自Song等, 2020). 柱状图表示中国古近纪盆地沉积速率 (数据源: 西宁和柴达木盆地, Fang等, 2019; 河西走廊盆地, Dai等, 2005; 渭河盆地, 孙文峰等, 2017; 南襄盆地, 马小林, 2012; 江汉盆地, Teng等, 2019; 湖北省地质矿产局, 1996; Huang和Hinnov, 2019; 四川盆地, 申琪, 2018; 苏北盆地, 钱勤和李坤英, 1996). (c) 珠江流域约44Ma以来剥露速 率变化. 根据珠江口盆地沉积速率(Clift, 2006)除以现代珠江流域面积计算

候-风化反馈，即这里的风化速率对气候变化依旧 敏感.

由于数据缺乏，很难直接确定晚渐新世季风加强 之前中国干旱亚热带地区的平均土壤组成. 然而，中 国北方广泛分布的黄土，作为干旱气候下遭受弱风化 的充分混合的上部大陆地壳物质(如Gallet等，1996), 可以近似代表古近纪干旱气候下土壤组成. 这种类比 的合理性在于目前的古环境重建表明极端干旱气候和 类似沙漠的地貌存在于早始新世中国亚热带地区(Sun
和Wang, 2005; Guo等, 2008), 例如其西部的盆地(贡觉 盆地, 图2b, Xiong等, 2020)和其南部内陆地区(衡阳盆 地, Xie等, 2020b). 中国南方地区在古近纪的这种类似 沙漠的地貌和风尘沉积(如Xiong等，2020)与现今中国 北方广泛分布的沙漠-黄土地貌类似. 黄土高原地区第 四纪黄土的成分均一，本文使用西峰(XF)更新世去碳 酸盐平均黄土成分(Liang等, 2009, 图1)代表现代干旱半干旱气候下的土壤组成(如石质土和雉形土, 本文土 壤分类沿用世界土壤参比基础WRB方案，见图3a). 该 

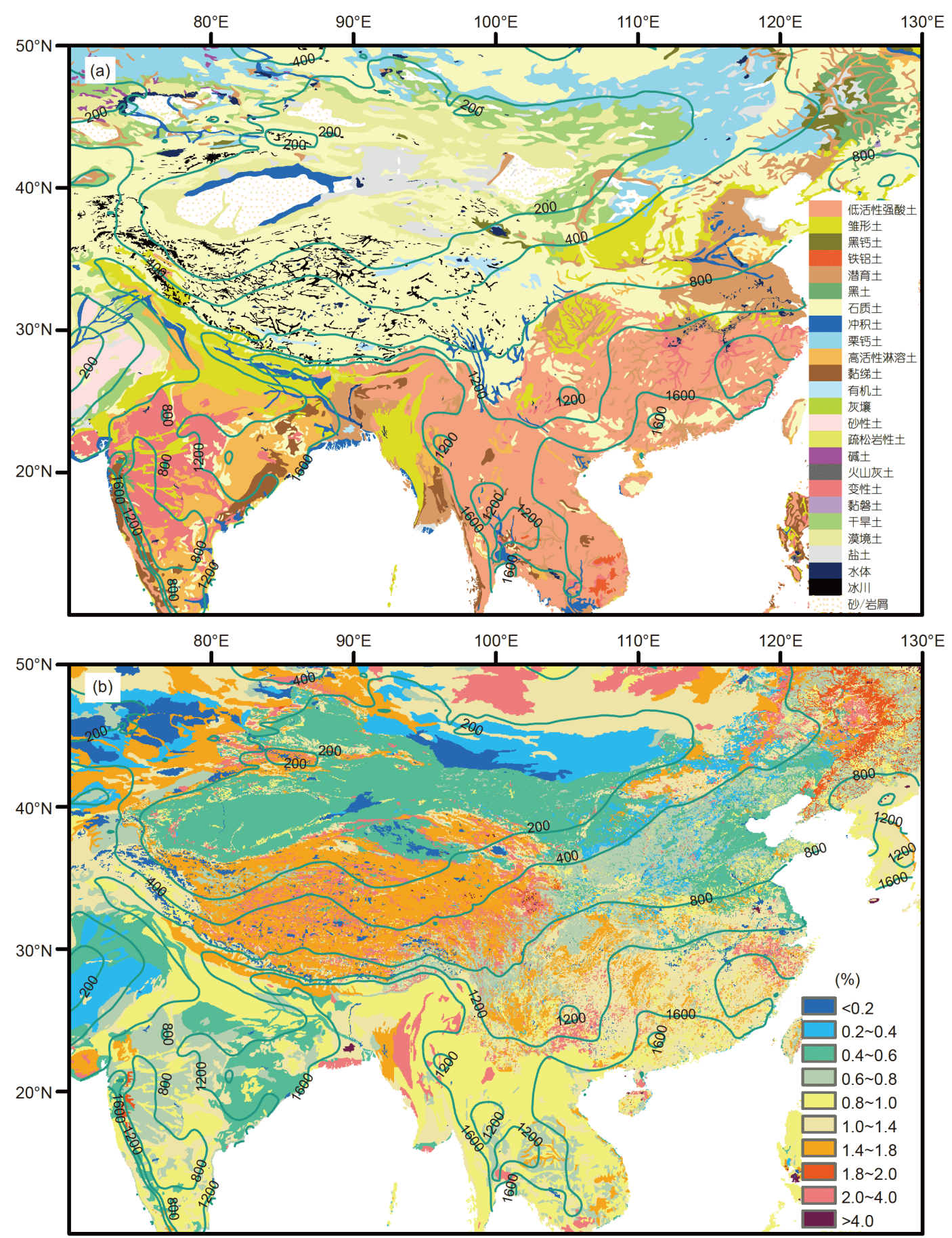

图 3 亚洲现代土壤类型和有机碳分布

(a) 亚洲现代土壤类型和降雨量 $(\mathrm{mm})$ 分布. 土壤类型数据基于FAO-UNESCO世界土壤图(http://www.fao.org/geonetwork/srv/en/main.home). (b) 亚洲土壤有机碳含量 $(\%)$ 和降雨量 $(\mathrm{mm})$ 分布. 有机碳数据来自于表层土壤 $(0 \sim 30 \mathrm{~cm}$, Wieder等, 2014). 等降雨量线数据来自CRU TS v3.24数据 库提供的高分辨率月气候观测网格数据(http://www.cru.uea.ac.uk/)

黄土平均成分的不确定性(见平均值的标准偏差, 网络 版附表1, http://earthcn.scichina.com)主要源于更新世
气候变化和风力分选导致的化学组成变化(如Yang等, 2006; Xiong等, 2010). 黄土中含碳酸盐, 但是其稀醋酸 
淋滤后的不溶成分可以代表季风加强之前干旱气候下 的土壤硅酸盐组成. 尽管如此, 现代中国北方黄土可能 和古近纪中国南方富 $\mathrm{Mg}$ 上地壳风化形成的土壤成分 并非完全一致, 这将给相关分析(如 $C_{\mathrm{sil}}$ 和 $\Delta_{\mathrm{sil}}$ 的计算)带 来偏差. 由于上地壳含 $\mathrm{Mg}$ 矿物的不均一性以及中国东 部富 $\mathrm{Mg}$ 上地壳的独特性，这种偏差可能仅仅体现在 $\Delta \mathrm{Mg}$ 的计算上(Gao等, 1991, 1998).

现代湿润的中国亚热带地区分布的典型土壤为红 壤和黄壤，他们约占中国红土分布面积的 $80 \%(\mathrm{He}$ 等， 2004). 本文使用了空间分布具有代表性的四个红壤数 据集和三个黄壤数据集的平均组成，代表中国亚热带 地区广泛分布的低活性强酸土组成(图3a; 网络版附表 1). 红壤数据集包括沿长江分布的第四纪红壤(洞庭湖, DTL, $1.2 \times 10^{4} \mathrm{~km}^{2}$ 的区域土壤数据, 张建新等, 2007 ; 九 江, JJ, 一个 $14 \mathrm{~m}$ 厚的红壤剖面, 宣城, XC, 一个 $10.4 \mathrm{~m}$ 厚 的红壤剖面, Hong等, 2013)和中国南部的红壤平均组 成(覆盖整个中国南部的 77 个土壤剖面 $\mathrm{A}$ 层数据; 中国 环境监测总站，1990). 黄壤数据集包括亚热带南部边 界附近的第四纪典型黄壤(南雄, $\mathrm{NX}$, 一个 $2.4 \mathrm{~m}$ 厚的黄 壤剖面; 田阳，TY，一个 $4.2 \mathrm{~m}$ 厚的黄壤剖面)以及中国 南部的黄壤平均组成(覆盖整个中国南部的 37 个土壤 剖面A层数据; 中国环境监测总站，1990)(网络版附表 1). 长江和黄河下游广泛分布的潜育土(图3a)是耕种土 壤, 其组成在本文中并未考虑.

南雄和田阳的黄壤样品为本研究提供的分析数 据. 样品经烘箱烘干后研磨成粉末, 然后经稀醋酸淋滤 处理. 稀醋酸淋滤基本不会释放硅酸盐的 Ca. 淋滤后 的不溶物用混合酸 $\mathrm{HNO}_{3} / \mathrm{HF}$ 高压密闭消解. 主量元素 在中国科学院青藏高原研究所用电感耦合等离子体光 谱仪(ICP-OES, Leeman Labs Prodigy-H)分析. 元素含 量数据基于淋滤后不溶物质量. 样品重复性分析表明 相对标准偏差 $<2 \%$. 除了南雄和田阳的黄壤样品数据 是基于醋酸淋滤不溶物成分，其他南方红土数据均为 全岩数据. 因为碳酸盐难以在南方土壤的低 $\mathrm{pH}$ 环境保 存, 所以这两类数据是可用来直接比较的.

为约束晚渐新世以来季风加强后全球和区域环境 变化对土壤硅酸盐组成的影响, 本文使用南海 ODP1146站(图1a)经稀醋酸淋滤的沉积物平均组成分 析 $\Delta_{\text {sil }}$ 的变幅. 南海沉积物反映了中国南部硅酸盐风化 的平均状况(如Liu等, 2003). ODP1146站硅酸盐风化指 标 $(\mathrm{Rb} / \mathrm{Sr} 、 \mathrm{CIA}$ 和黏土矿物组合)显示约 $20 \mathrm{Ma}$ 以来整
体不断降低的风化强度, 其中早中中新世是强的风化 时期而上新世-第四纪为非常弱的风化时期(Wan等, 2010). 基于上述风化强度的历史变化, 本文使用 15 19Ma(SCS 15 19Ma)以及0 5Ma(SCS 0 5Ma)两 个时期的成分平均值来分别代表强弱两个风化阶段的 沉积物组成. 本文使用这两个阶段的沉积物数据分析 季风加强后土壤硅酸盐组成变化, 并采用上述 $\Delta_{\text {sil }}$ 的计 算方法, 比较他们与中国北方干旱区黄土的成分差异.

\section{2 有机碳埋藏消耗 $\mathrm{CO}_{2}$ 的定量方法}

季风加强前后有机碳埋藏的变化 $\left(\Delta_{\mathrm{oc}}\right)$ 可以通过分 析东亚边缘海碎屑沉积物中陆源有机碳含量的差异来 获得. 但是边缘海沉积物数据不能直接分析 $\Delta_{\mathrm{oc}}$; 因为 区分陆源和海洋自生有机碳在总有机碳中占比是十分 困难的, 特别是在海洋有机质占主导的情况下(Shipboard Scientific Party, 2000). 与孟加拉扇的研究方法 类似(如Galy等, 2007; Lee等, 2019), 本文假定 $\Delta_{\mathrm{oc}}$ 主要 受控于陆源有机质产量和陆源有机质在海洋沉积物中 的埋藏效率. 因此 $\Delta_{\mathrm{oc}}$ 可表示为

$\Delta_{\mathrm{oc}}=M_{\mathrm{a}} \times f_{\mathrm{a}}-M_{\mathrm{b}} \times f_{\mathrm{b}}$,

这里 $M$ 为土壤有机碳含量, $f$ 为有机碳埋藏效率(有机碳 保存在海洋沉积物中的百分比), 下标 $\mathrm{a}$ 和 $\mathrm{b}$ 分别代表季 风加强之后和之前的情景.

\section{3 降水变化对构造隆升的响应}

为约束山脉隆升对中国东部季风区降水变化的影 响，本文使用气候模拟手段去检验古近纪和现代地形 差异造成的降水变化. 模型的边界条件变化为青藏高 原北部的地形变化. 这是因为青藏高原北部隆升对于 东亚季风的影响更加显著(Liu等, 2015; Tada等, 2016; Zhang等, 2017), 并且青藏高原北部由隆升驱动的显著 地形变化也主要始于晚渐新世(如Tapponnier等, 2001; Lin等, 2020; Li等, 2021; Yang等, 2021a). 本文因此开 展基于两个不同地形的试验：第一个试验利用现代地 形和参数(图4a)，第二个试验去除青藏高原北部地形 来反映晚渐新世之前的状况(图4b). 因此, 两个试验的 差别可以用来分析青藏高原北部隆升对气候的影响.

本文使用美国国家大气研究中心(NCAR)开发的 通用地球系统模式(Community Earth System Model version 1.2.2, CESM1.2.2). 该模型包含了大气、海 
(a)现代

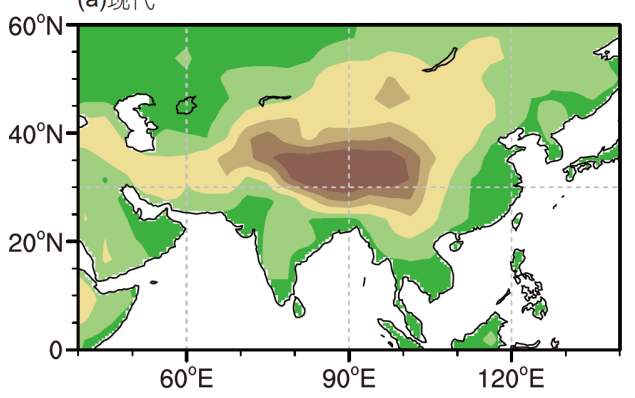

(b)青藏高原北部地形移除

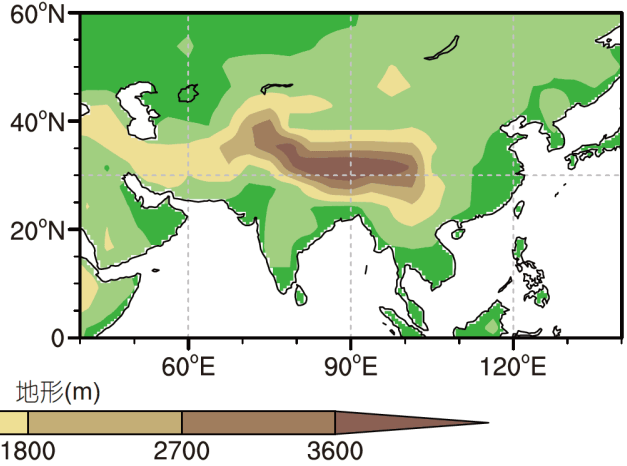

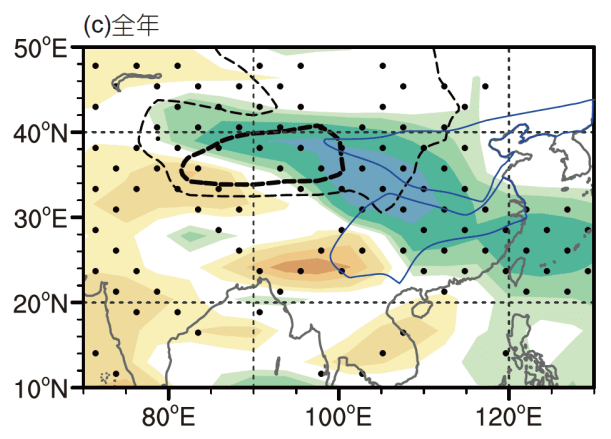
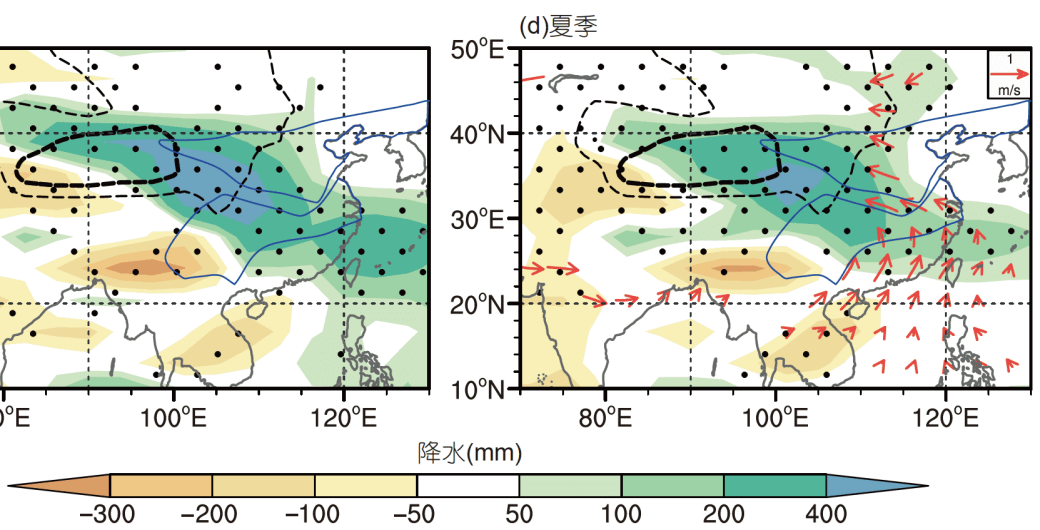

图 4 青藏高原北部隆升的气候模拟试验

现代(a)以及去除青藏高原北部(b)的亚洲地形。基于不同地形的两个气候模拟试验产生的年降雨量(c)和夏季降雨量(d)的差异(基于地形(a)的 试验减去基于地形(b)的试验). 斑点区域对应于降水变化置信限大于 $95 \%$ 区域(使用Student's $t$-test). 黑色粗虚线和细虚线分别对应 $1500 \mathrm{~m}$ 和 $500 \mathrm{~m}$ 的地形去除区域. 蓝色线是扬子和华北克拉通分布区域

洋、陆地、径流、海冰、陆冰和海浪等模块以及一个 耦合器. 本研究使用了上述前五个模块和耦合器进行 模拟研究(详见Zhang等, 2019)。两个试验均在 $560 \mathrm{ppmv}$ 的大气 $\mathrm{CO}_{2}$ 含量条件下运行 $(1 \mathrm{ppmv}=1 \mu \mathrm{L}$ $\left.\mathrm{L}^{-1}\right)$. 该大气 $\mathrm{CO}_{2}$ 含量高于现代值, 接近于晚渐新世时 期各种指标重建的大气 $\mathrm{CO}_{2}$ 含量(Beerling 和Royer, 2011; Zhang等, 2013). 含氯氟烃含量(CFCs) 设定为 0 , $\mathrm{CH}_{4}$ 和 $\mathrm{N}_{2} \mathrm{O}$ 分别设定为 $760 \mathrm{ppbv}$ 和 $270 \mathrm{ppbv}(1 \mathrm{ppbv}=1 \mathrm{~nL}$ $\left.\mathrm{L}^{-1}\right)$. 其他参数, 包括 $\mathrm{O}_{3}$ 、气溶胶含量、太阳常数和轨 道参数均设定为工业革命前数值. 两个试验均运行了 1700 模式年, 使得大气和海洋表层达到准平衡状态. 本研究分析和使用每个试验最后 50 年的数据.

\section{4 晚渐新世季风加强期的侵蚀速率变化}

分析季风加强导致硅酸盐风化和有机碳埋藏的通 量变化, 需要计算上地壳物质的侵蚀量变化. 下文将详
述侵蚀通量变化的重建方法.

现代中国亚热带地区的物理侵蚀速率变化很大. ${ }^{10} \mathrm{Be}$ 数据揭示侵蚀速率从低地势地区 $20 \sim 50 \mathrm{~mm} \mathrm{ka}^{-1}$ 增 加到陡峭、滑坡主导的山地区域700 900 $\mathrm{mm} \mathrm{ka}^{-1}$ (Chappell等，2006). 长江流域主要位于本文研究的季 风加强区域(图1a), 并占研究区面积的 $59 \%$. 另外, 长江 流经具有各种地貌和气候的区域，提供了整个研究区 侵蚀速率的平均状况. 因此, 通过外推长江流域 $480 \times 10^{6} \mathrm{t} \mathrm{a}^{-1}$ 的侵蚀速率(Milliman和Syvitski，1992)可 以得出研究区 (总面积约为 320 万平方公里)物理侵蚀 速率约为 $800 \times 10^{6} \mathrm{t} \mathrm{a}^{-1}$.

本文进一步假定研究区侵蚀通量的长期变化与中 国东部边缘海盆地记录的沉积物通量变化一致. 但是 东亚边缘海新生代沉积通量的重建显示了渐新世以来 不同的长期演化过程(Métivier等, 1999; Clift等, 2004). Clift等(2004)的结果包含了珠江、东海和渤海湾的数 
据, 显示了中中新世和第四纪为沉积通量峰值的长期 变化(Clift等, 2004). Métivier等(1999)的结果包括了东 海、台湾北部、冲绳、黄海和渤海的数据, 沉积通量 呈现出单调增加的长期变化. 辨析这两个重建结果的 沉积通量变化超出了本文的研究内容. 本文使用上文 分析的研究区现代侵蚀通量乘以这两条沉积通量的相 对变化(沉积通量相对变化通过某一时间点的沉积通 量除以该研究的沉积通量最高值获得), 来重建晚渐新 世以来与中国亚热带地区气候重组有关的侵蚀通量 变化.

\section{3 硅酸盐蚀变程度和有机碳埋藏}

\section{1 硅酸盐蚀变和 $\mathrm{Mg}$ 的贡献}

$C_{\text {sil }}$ 分析结果表明: 无论在湿润的中国亚热带地区 还是干旱的中国北方地区, $\mathrm{Ca}$ 硅酸盐 $\left(\Delta \mathrm{Ca}_{0}\right)$ 在硅酸盐 风化中都占了相对高的比例, 但是 $\mathrm{Mg}$ 硅酸盐 $\left(\Delta \mathrm{Mg}_{0}\right)$ 的 贡献却大相径庭(图 $5 \mathrm{a}$, 网络版附表2), 这里定义新的 参数 $C_{\mathrm{sil}}{ }^{*}\left(C_{\mathrm{sil}}{ }^{*}=C_{\mathrm{sil}}-\Delta \mathrm{Mg}_{0}\right)$ 用来揭示 $\mathrm{Ca}-\mathrm{Na}-\mathrm{K}$ 硅酸盐矿 物(主要为长石矿物)风化对 $\mathrm{CO}_{2}$ 消耗的贡献. 对于南海 沉积物、红壤和黄壤, $C_{\mathrm{sil}}{ }^{*}$ 和 $C_{\mathrm{sil}}$ 的差值非常大, 而对于 西峰黄土其差值却很小. $C_{\mathrm{sil}}{ }^{*}$ 和 $C_{\mathrm{sil}}$ 的差值反映了风化 行为在不同气候区的差异: 相比于干旱的中国西北地 区, 湿润的中国亚热带地区的硅酸盐风化存在更大程 度的 $\mathrm{Mg}$ 亏损. 此外, 南海沉积物 $\Delta_{\mathrm{sil}} / C_{\mathrm{sil}}$ 的比值约为 $50 \%$, 而亚热带土壤约为 $60 \%$, 这表明中国南方地区在 季风加强前后的硅酸盐风化差异导致了显著的阳离子 亏损.

$\Delta_{\text {si }}$ 适合描述晚渐新世季风加强引起的硅酸盐蚀 变程度的变化. 同样地, 这里使用 $\Delta_{\mathrm{sil}}{ }^{*}\left(\Delta_{\mathrm{sil}}{ }^{*}=\Delta_{\mathrm{sil}}-\Delta \mathrm{Mg}\right)$ 来揭示晚渐新世季风加强引起的 $\mathrm{Ca}-\mathrm{Na}-\mathrm{K}$ 硅酸盐矿物 (主要为长石矿物) 风化增强对 $\mathrm{CO}_{2}$ 的消耗. $\Delta_{\mathrm{sil}}$ 和 $\Delta_{\mathrm{sil}}{ }^{*}$ 的 差值指示了 $\Delta \mathrm{Mg}$ 的平均贡献大于 $60 \%$ (网络版附表3). 南海沉积物 $\Delta_{\text {sil }}{ }^{*}$ 的分布范围为 $0.15 \sim 0.21 \mathrm{~mol} \mathrm{~kg}^{-1}$, 而现 代土壤为 $0.25 \sim 0.33 \mathrm{~mol} \mathrm{~kg}^{-1}$ (图5b). 南海沉积物 $\Delta_{\mathrm{si1}}$ 和 $\Delta_{\text {sil }}$ 在 15 19Ma和0 5Ma两个时期的差异(网络版附表 3 )表明新近纪气候或者物源对 $\Delta_{\mathrm{sil}} *$ 和 $\Delta_{\mathrm{sil}}$ 的影响在 20 30\%. 上述 $\Delta_{\mathrm{sil}}{ }^{*}$ 与孟加拉扇ODP116站(图1)硅酸盐 风化消耗的 $\mathrm{CO}_{2}$ 量 $\left(C_{\mathrm{sil}}\right)$ 相当. 孟加拉扇富伊利石-绿泥 石沉积物 $C_{\mathrm{sil}}$ 为 $0.17 \mathrm{~mol} \mathrm{~kg}^{-1}$, 其中几乎没有 $\Delta \mathrm{Mg}_{0}$ 贡献; 而富蒙脱石-高岭石 $C_{\mathrm{sil}}$ 为 $0.23 \mathrm{~mol} \mathrm{~kg}^{-1}$, 其中 $\Delta \mathrm{Mg}_{0}$ 贡献
不足 $0.03 \mathrm{~mol} \mathrm{~kg}^{-1}$ (图5a; France-Lanord和Derry, 1997). 上述对比表明排除 $\mathrm{Mg}$ 的贡献后, 硅酸盐风化消耗 $\mathrm{CO}_{2}$ 的程度在这两个地区是相当的.

综上, 中国亚热带地区季风加强引起的硅酸盐风 化程度差异主要来自于 $\mathrm{Mg}$ 硅酸盐的风化, 这可能与中 国东部上地壳具有相对高的 $\mathrm{Mg}$ 含量有关(如 $\mathrm{Gao}$ 等, 1991，1998). 首先, 全球和区域上部大陆地壳组成中 $\mathrm{TiO}_{2} / \mathrm{Al}_{2} \mathrm{O}_{3}$ 和 $\mathrm{MgO} / \mathrm{Al}_{2} \mathrm{O}_{3}$ 呈正相关(图6a), 表明上部大 陆地壳Ti和 $\mathrm{Mg}$ 的相对丰度存在紧密联系. 中国东部去 碳酸盐的上部大陆地壳具有最高的 $\mathrm{TiO}_{2} / \mathrm{Al}_{2} \mathrm{O}_{3}$ 和 $\mathrm{MgO} /$ $\mathrm{Al}_{2} \mathrm{O}_{3}$ 比值(图6a), 指示了中国东部上地壳硅酸盐存在 更多的铁镁质成分. 其次, 南亚地区高喜马拉雅结晶 岩低的 $\mathrm{MgO}$ 含量(1.76\%)也与非常低的 $\mathrm{Mg}$ 硅酸盐风化 贡献相符(France-Lanord和Derry, 1997). 再次, 长江的 细颗粒沉积物硅酸盐 $\mathrm{MgO}$ 含量(平均值 $3.12 \%, n=30$, $\mathrm{He}$ 等，2015)明显高于源自干旱亚洲内陆的西峰黄土 $\mathrm{MgO}$ 含量 $(2.76 \%, n=15$, Liang等, 2009; 网络版附表1). 中国东部去碳酸盐的上部大陆地壳组成相对于其他地 区上地壳(如加拿大前寒武地盾, Shaw等, 1967)具有更 多的未变质盖层物质; 而这些盖层被认为包含更多的 铁镁质火山物质(Gao等, 1998; Rudnick和Gao, 2004). 因此, 中国亚热带地区高的 $\Delta \mathrm{Mg}$ 贡献主要来源于以下 两个因素: (1) 富 $\mathrm{Mg}$ 上地壳岩石更容易在风化中蚀变; (2) 季风加强导致了中国东部上地壳岩石风化加剧, 而 风化加剧导致的盐基离子净亏损包含了相当比例的富 $\mathrm{Mg}$ 硅酸盐风化贡献. 各种沉积物和土壤的 $\mathrm{TiO}_{2} / \mathrm{Al}_{2} \mathrm{O}_{3}$ (母岩中铁镁质物质含量的敏感指标)和基于黄土计算 的 $\mathrm{CO}_{2}$ 消耗 $(\Delta \mathrm{Ca} 、 \Delta \mathrm{Na} 、 \Delta \mathrm{Mg}$ 和 $\Delta \mathrm{K})$ 的协变关系分析 表明 $\mathrm{TiO}_{2} / \mathrm{Al}_{2} \mathrm{O}_{3}$ 仅和 $\Delta \mathrm{Mg}$ 呈现显著正相关(图6b), 进一 步证明 $\Delta \mathrm{Mg}$ 的变化主要源自于铁镁质矿物的风化. 在 湿润气候下红壤和黄壤中低的 $\mathrm{MgO}$ 含量表明晚渐新 世气候重组后中国东部上地壳风化导致显著的硅酸盐 $\mathrm{Mg}$ 亏损.

\section{2 有机碳埋藏}

为分析 $\Delta_{\mathrm{oc}}$, 本文首先确定有机碳埋藏效率 $f$. 前人 研究表明高的 $f$ 值主要源于高侵蚀或者快速沉积体系 (Blair和Aller, 2012), 如孟加拉扇(Galy等, 2007)和山区 小型河流(如台湾, Hilton等, 2011; Blair和Aller, 2012). 晚渐新世季风加强后, 中国亚热带地区较之前产生更 多沉积物并通过河流搬运到海洋(如Métivier等, 1999; 


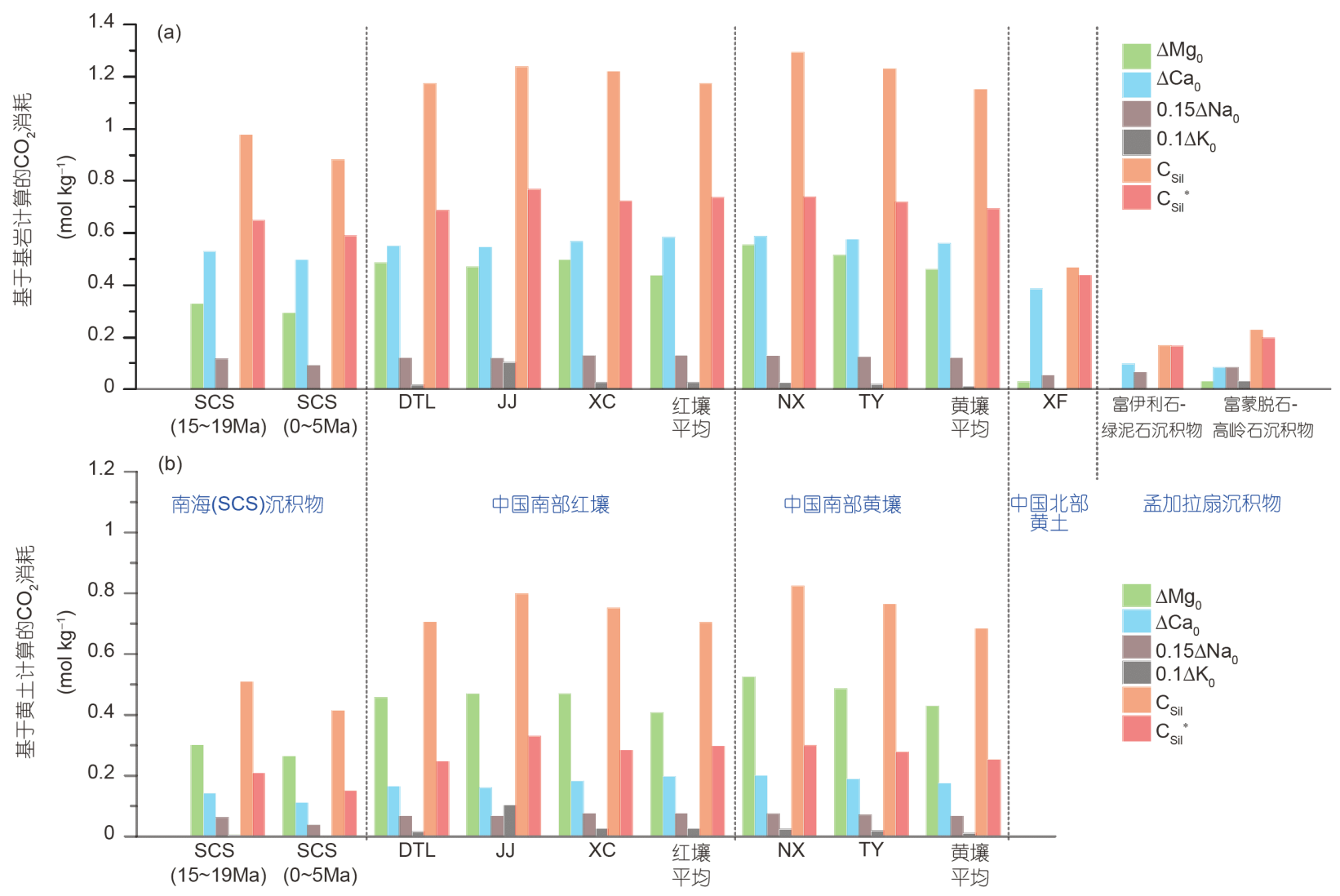

图 5 硅酸盐风化导致的 $\mathrm{CO}_{2}$ 消耗

(a) 硅酸盐风化导致的 $\mathrm{CO}_{2}$ 消耗, 通过分析各种沉积物和基岩的化学成分差异所得. 孟加拉扇沉积物对应的 $\mathrm{CO}_{2}$ 消耗根据未蚀变的喜马拉雅山 脉岩石组成计算(France-Lanord和Derry, 1997); 其他沉积物对应的 $\mathrm{CO}_{2}$ 消耗根据去除碳酸盐的中国东部上地壳组成(Gao等, 1998)计算. (b) 晚 渐新世季风加强硅酸盐风化导致的 $\mathrm{CO}_{2}$ 消耗差异, 通过计算季风影响区各类沉积物和土壤(如南海沉积物和中国南部各种土壤)与中国西北干 旱区黄土成分差异所得

Clift等，2004)。长江是中国亚热带地区物质向海洋输 送的主要河流. 这里保守地假定 $f_{\mathrm{a}}$ 和 $f_{\mathrm{b}}$ 均为现代长江沉 积物陆源有机质的保存效率30\%(Blair和Aller，2012), 计算所得的 $\Delta_{\mathrm{oc}}$ 为最小值.

中国亚热带地区绝大部分地区现代土壤表层 $(0 \sim 30 \mathrm{~cm})$ 有机碳含量分布在 $0.8 \sim 1.8 \%$, 而中国北方干 旱地区分布在 $0.4 \sim 0.8 \%$ (图 $2 b$ ). 中国亚热带地区(不包 括中国东部的耕种土壤)面积加权平均值为 $(1.3 \pm 0.6) \%$ 而中国北方干旱区为 $(0.7 \pm 0.3) \%$. 东亚和南亚地区基岩 的化石有机碳含量约为 $0.2 \%$ (France-Lanord和Derry, 1997; Hilton等，2011). 假设化石有机碳埋藏效率为 $100 \%$, 那么 $M_{\mathrm{a}}$ 和 $M_{\mathrm{b}}$ 分别为 0.89 和 $0.39 \mathrm{~mol} \mathrm{~kg}^{-1}$, 而 $\Delta_{\mathrm{oc}}$ 为 $0.15 \mathrm{~mol} \mathrm{C} \mathrm{kg}^{-1}$. 中国亚热带地区 $\Delta_{\mathrm{oc}}$ 的估算值小于 $\Delta_{\text {sil }}$ (平均值 $0.60 \mathrm{~mol} \mathrm{~kg}^{-1}$ ), 显示有机碳埋藏对 $\mathrm{CO}_{2}$ 消耗 的贡献小于硅酸盐风化. 这与喜马拉雅地区显著不同.
在喜马拉雅地区有机碳埋藏对 $\mathrm{CO}_{2}$ 的消耗是远大于硅 酸盐风化的(France-Lanord和Derry, 1997).

\section{4 讨论}

\section{1 季风加强与 $M g$ 通量}

季风增强加剧硅酸盐风化导致的 $\mathrm{Mg}$ 通量变化 $F_{\mathrm{Mg} \text {, sil }}$ 可以表示为

$F_{\mathrm{Mg}, \mathrm{sil}}=E_{\mathrm{a}} \times \Delta \mathrm{Mg}_{0, \mathrm{a}}-E_{\mathrm{b}} \times \Delta \mathrm{Mg}_{0, \mathrm{~b}}$,

这里 $E$ 是沉积物通量 $\left(\mathrm{kg} \mathrm{a}^{-1}\right)$, 对应于本文重建的研究区 侵蚀通量(图7a). $\Delta \mathrm{Mg}_{0, \mathrm{~b}}$ 为 $0.03 \mathrm{~mol} \mathrm{~kg}^{-1}$, 与西峰黄土对 应(图5a). $\Delta \mathrm{Mg}_{0, \mathrm{~b}}$ 为 $0.45 \mathrm{~mol} \mathrm{~kg}^{-1}$, 采用中国亚热带地区 土壤和南海沉积物 $\Delta \mathrm{Mg}_{0}$ 平均值 $(0.45 \pm 0.09) \mathrm{mol} \mathrm{kg}^{-1}$ (图5). 

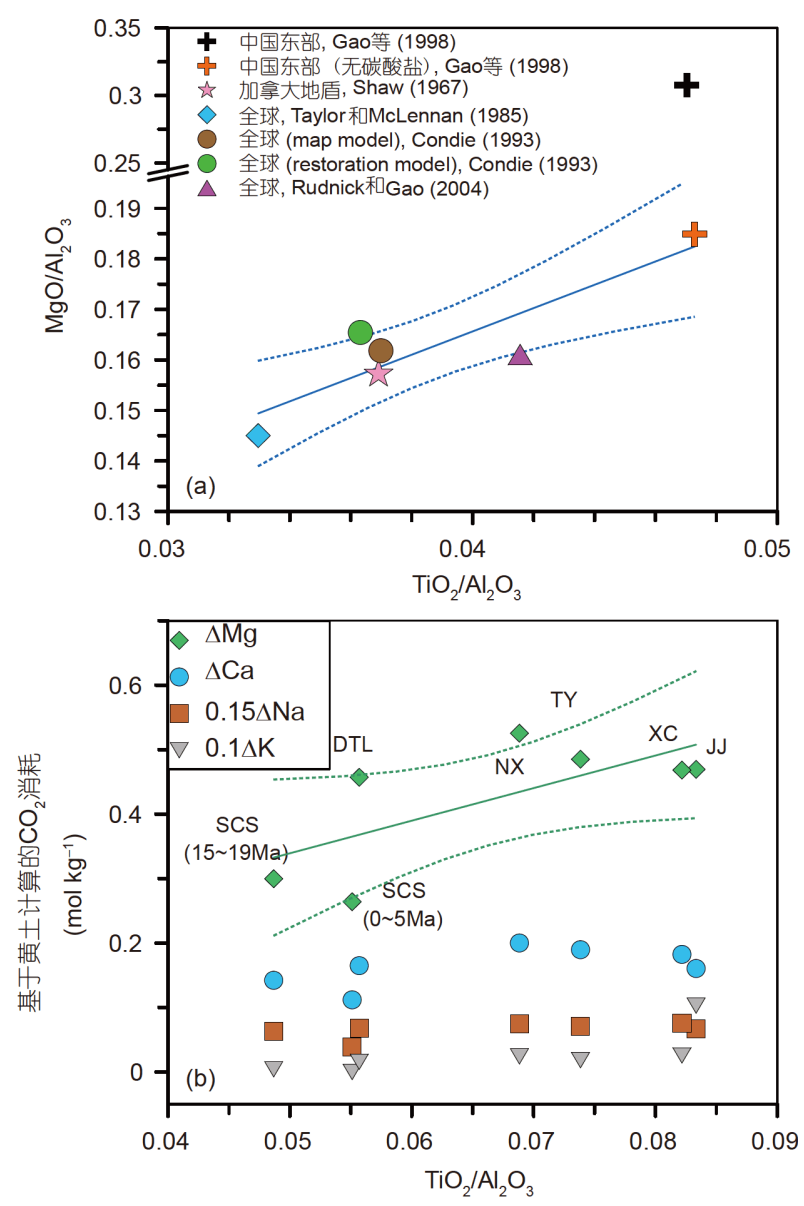

图 $6 \mathrm{TiO}_{2} / \mathrm{Al}_{2} \mathrm{O}_{3}$ 和 $\mathrm{Mg}$ 亏损程度的对应关系

(a) 全球和区域大陆上地壳 $\mathrm{TiO}_{2} / \mathrm{Al}_{2} \mathrm{O}_{3}$ 和 $\mathrm{MgO} / \mathrm{Al}_{2} \mathrm{O}_{3}$ 协变关系图. 蓝. 色为线性拟合线(未包含中国东部数据, $R^{2}=0.80, p=0.02$ ). (b) 各种沉 积物和土壤的 $\mathrm{TiO}_{2} / \mathrm{Al}_{2} \mathrm{O}_{3}$ 和基于黄土计算的硅酸盐 $\mathrm{Mg} 、 \mathrm{Ca} 、 \mathrm{Na}$ 和 $\mathrm{K}$ 对应大气 $\mathrm{CO}_{2}$ 消耗的协变关系图. 其中只有 $\mathrm{TiO}_{2} / \mathrm{Al}_{2} \mathrm{O}_{3}$ 与 $\Delta \mathrm{Mg}$ 存在 显著相关(线性拟合, $R^{2}=0.53, p=0.06$ ). 图(a)和(b)中的虚线为线性拟 合的 $95 \%$ 置信区间

另外, 中国东部沉积盖层含有相当数量的白云岩 (Gao等，1991)，这可以从中国东部上地壳全岩和去碳 酸盐两种组成具有显著的 $\mathrm{MgO} / \mathrm{Al}_{2} \mathrm{O}_{3}$ 差值得到证明 (图6a). 因此, 研究区风化加强将会溶解大量富 $\mathrm{Mg}$ 碳酸 盐, 并经河流搬运进入海洋循环. 获取中国东部上地壳 碳酸盐 $\mathrm{Mg}$ 和 $\mathrm{Ca}$ 的平均含量可以通过比较上地壳全岩 和去碳酸盐组成(Gao等，1998)来计算. 假设 $\mathrm{Si}$ 仅存在 于硅酸盐中, 那么碳酸盐中 $\mathrm{Mg}$ 的摩尔含量 $\left([\mathrm{Mg}]_{\mathrm{carb}}\right.$, $\mathrm{mol} \mathrm{kg}{ }^{-1}$ )可以表示为

$[\mathrm{Mg}]_{\text {carb }}=[\mathrm{Mg}]_{\text {bulk }}-[\mathrm{Mg}]_{\text {sil }} /[\mathrm{Si}]_{\text {bulk }} \times[\mathrm{Si}]_{\mathrm{sil}}$,

这里下标bulk和sil表示中国东部上地壳全岩和去碳酸

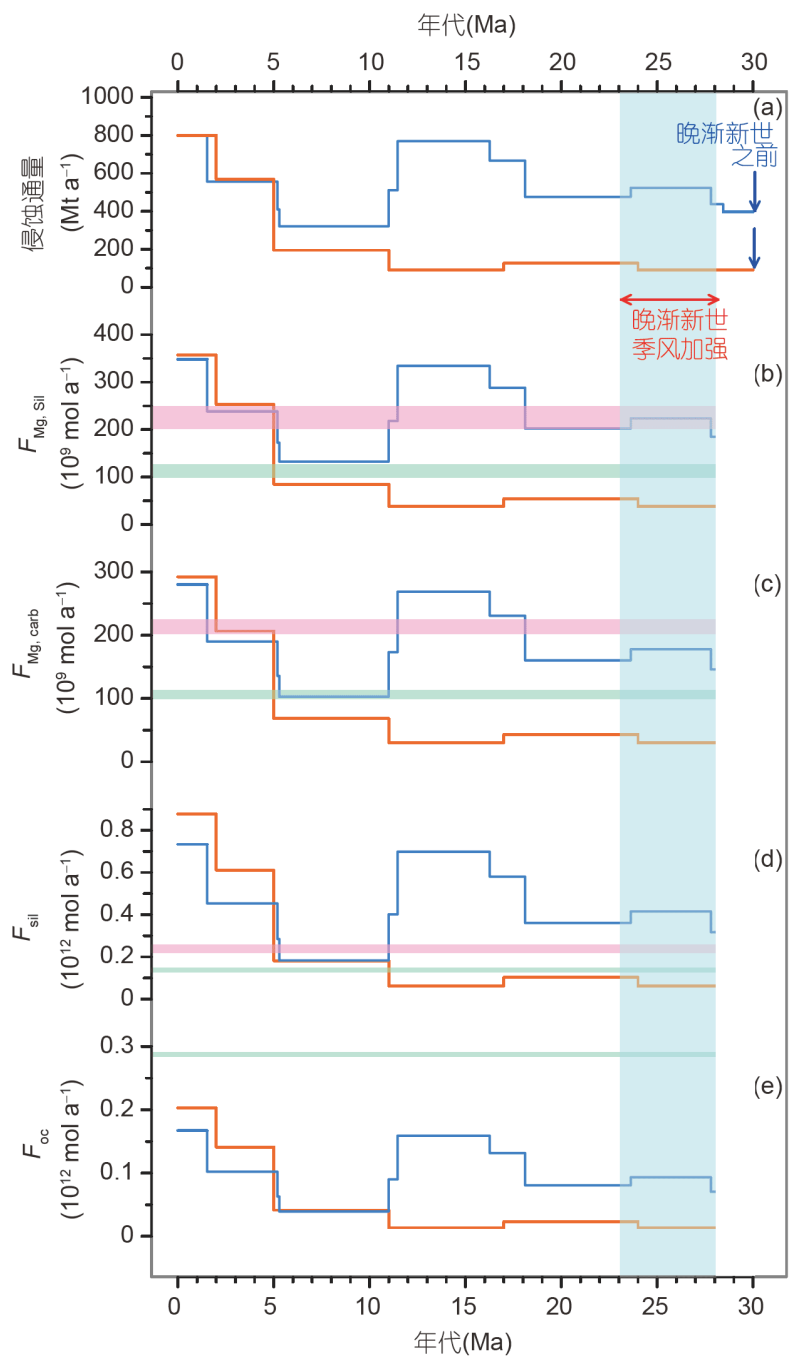

图 7 侵蚀、风化和有机碳埋藏通量

(a) 晚渐新世季风加强有关的侵蚀通量; (b) 硅酸盐风化 $\mathrm{Mg}$ 释放通量 $\left(F_{\mathrm{Mg}, \text { sil }}\right)$; (c) 碳酸盐风化 $\mathrm{Mg}$ 释放通量 $\left(F_{\mathrm{Mg}, \mathrm{carb}}\right)$; (d) 硅酸盐风化导致 的 $\mathrm{CO}_{2}$ 消耗通量; (e) 有机碳埋藏通量. 图(a) (e)中的蓝色和橙色曲 线分别基于Clift等(2004)和Métivier等(1999)重建的中国东部边缘海 沉积通量变化计算. (a)中研究区侵蚀通量使用本文分析的研究区现 代侵蚀通量(约 $800 \times 10^{6} \mathrm{t} \mathrm{a}^{-1}$ ) 乘以上述两种重建沉积通量的相对变 化. (a)中蓝色箭头为本文中选取的晚渐新世气候重组之前的侵蚀通 量. 图(b) (e)粉色和绿色条带分别为对应变量的 $10 \%$ 和 $5 \%$ 全球通量. 其中图(d)中粉色和绿色条带根据现代全球 $\mathrm{Ca}-\mathrm{Mg}$ 硅酸盐风化通量 $\left(2.17 \times 10^{12} \sim 2.5 \times 10^{12} \mathrm{~mol} \mathrm{a}^{-1}\right)$ 计算, 因为本文计算的长期 $\mathrm{CO}_{2}$ 消耗通 量 $\left(F_{\text {sil }}\right.$, 主要为 $\mathrm{Ca}-\mathrm{Mg}$ 硅酸盐风化贡献 $)$ 不能直接与现代大陆硅酸盐 风化通量 $\left(7.85 \times 10^{12} \sim 8.7 \times 10^{12} \mathrm{~mol} \mathrm{a}^{-1}\right)$ 直接比较, 详见4.2讨论

盐组成; 式中 $\mathrm{Mg}$ 和 $\mathrm{Si}$ 使用摩尔含量. 经上式计算, $[\mathrm{Mg}]_{\mathrm{carb}}$ 为 $0.37 \mathrm{~mol} \mathrm{~kg}^{-1}$. 用方程 (6)的类似方法计算 $[\mathrm{Ca}]_{\mathrm{carb}}$ 为 $0.80 \mathrm{~mol} \mathrm{~kg}^{-1}$, 那么中国东部上地壳碳酸盐 
$\mathrm{Mg} / \mathrm{Ca}$ 摩尔比值为 0.46 . 假定白云石 $\mathrm{Mg} / \mathrm{Ca}$ 摩尔比值为 1 , 而方解石为 0.08 (该值为中国东部太古宙后碳酸盐 平均值的下限, Gao等, 1991); 据此估算东部上地壳碳 酸盐约 $50 \%$ 为白云石. 相对于方解石, 白云石在干旱半干旱气候下是难以溶解的(如在中国西北干旱区, Meng等, 2015). 因此这里假定仅方解石在晚渐新世季 风加强前的干旱气候下溶解, 而方解石和白云石均可 在季风加强后的湿润气候下溶解. 那么季风加强驱动 碳酸盐风化导致的 $\mathrm{Mg}$ 通量变化, $F_{\mathrm{Mg} \text {, sil, }}$, 可表示为

$F_{\mathrm{Mg}, \text { carb }}=E_{\mathrm{a}} \times[\mathrm{Mg}]_{\text {carb, a }}-E_{\mathrm{b}} \times[\mathrm{Mg}]_{\mathrm{carb}, \mathrm{b}}$,

这里 $[\mathrm{Mg}]_{\mathrm{carb}, \mathrm{a}}$ 为 $0.37 \mathrm{~mol} \mathrm{~kg}^{-1}$, 对应于中国东部上地壳 碳酸盐(方解石和白云石)中的 $\mathrm{Mg}$ 含量, 而 $[\mathrm{Mg}]_{\text {carb, b }}$ 为 $0.04 \mathrm{~mol} \mathrm{~kg}^{-1}$, 对应于中国东部上地壳方解石中 $\mathrm{Mg}$ 含 量(使用方解石 $\mathrm{Mg} / \mathrm{Ca}$ 摩尔比值为 0.08 计算).

根据Clift等(2004)的沉积通量变化计算的研究区 侵蚀通量(后续简称为Clift模型，图7a)，晚渐新世以来 东亚季风增强加剧硅酸盐风化导致的 $\mathrm{Mg}$ 释放通量 $\left(F_{\mathrm{Mg}, \text { sil }}\right)$ 变化在 $0.13 \times 10^{12} \sim 0.35 \times 10^{12} \mathrm{~mol} \mathrm{a}^{-1}$. 根据Métivier等(1999)的沉积通量变化计算的研究区侵蚀通量

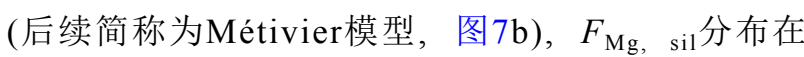
$0.03 \times 10^{12} \sim 0.36 \times 10^{12} \mathrm{~mol} \mathrm{a}^{-1}$. 同样，碳酸盐风化释放的 $\mathrm{Mg}$ 通量 $\left(F_{\mathrm{Mg}}\right.$, carb $)$ 变化在 $0.10 \times 10^{12} \sim 0.28 \times 10^{12} \mathrm{~mol} \mathrm{a}^{-1}$ (Clift模型)或 $0.03 \times 10^{12} \sim 0.29 \times 10^{12} \mathrm{~mol} \mathrm{a}^{-1}$ (Métivier模 型)之间(图7c). 硅酸盐和碳酸盐风化释放的总 $\mathrm{Mg}$ 通量 $\left(F_{\mathrm{Mg}, \mathrm{sil}}+F_{\mathrm{Mg}, \mathrm{carb}}\right)$ 约占现代全球硅酸盐和碳酸盐风化释 放总 Mg通量的 5.0 16\%(Clift模型)或1.5 16\%(Métivier 模型). 这里, 现代全球硅酸盐和碳酸盐风化释放的 $\mathrm{Mg}$ 通量分别为 $2 \times 10^{12} \sim 2.5 \times 10^{12} \mathrm{~mol} \mathrm{a}^{-1}$ 和 $2 \times 10^{12}$ $2.2 \times 10^{12} \mathrm{~mol} \mathrm{a}^{-1}$ (Higgins和Schrag, 2015).

新生代海洋 $\mathrm{Mg}$ 循环的特征之一, 就是由海相石盐 原生包裹体揭示的新近纪海水 $\mathrm{Mg}$ 含量增加(图 $8 \mathrm{c}$; Zimmermann, 2000; Horita等, 2002). 但是其机制尚存 在争议: 如碳酸盐风化导致的 $\mathrm{Mg}$ 输入增加( $\mathrm{Li}$ 和Elderfield，2013)或者海洋中Mg移除速率的降低(如Coggon 等, 2010; Higgins和Schrag, 2015; Dunlea等, 2017). 海 水 $\mathrm{Mg}$ 含量从 $37 \mathrm{Ma}$ 的 $38 \mathrm{mmol} \mathrm{kg}^{-1}$ 增加到现代的 $55.1 \mathrm{mmol} \mathrm{kg}^{-1}$ (Horita等, 2002)需要约 $0.46 \mathrm{mmol} \mathrm{Ma}^{-1}$ 的平均增长速率. 晚渐新世以来东亚地区硅酸盐和碳 酸盐风化释放的总 $\mathrm{Mg}$ 通量可以贡献的海水 $\mathrm{Mg}$ 含量增 加速率为 $0.17 \sim 0.45 \mathrm{mmol} \mathrm{Ma}^{-1}$ (Clift 模型) 或
0.05 0.46 $\mathrm{mmol} \mathrm{Ma}^{-1}$ (Métivier模型). 本研究揭示了新 近纪海水 $\mathrm{Mg}$ 含量的增加至少有相当显著的比例来自 于中国东部 $\mathrm{Mg}$ 硅酸盐和富白云石碳酸盐的风化输入 (图8a、8b).

\section{2 季风加强与碳通量}

与 $\mathrm{Mg}$ 通量的计算类似, 季风加强导致硅酸盐风化 引起的长期 $\mathrm{CO}_{2}$ 消耗 $\left(F_{\mathrm{sil}}\right)$ 可以表示为

$F_{\text {sil }}=E_{\mathrm{a}} \times C_{\text {sil a }}-E_{\mathrm{b}} \times C_{\mathrm{sil}, \mathrm{b}}$,

这里 $C_{\mathrm{sil}}$, a $1.15 \mathrm{~mol} \mathrm{~kg}^{-1}$, 采用南海和中国亚热带土壤 平均 $C_{\mathrm{si} 1}$ 值 $(1.15 \pm 0.13) \mathrm{mol} \mathrm{kg}^{-1}$ (图 5); $C_{\mathrm{sil} 1, \mathrm{~b}}$ 为 $0.47 \mathrm{~mol} \mathrm{~kg}^{-1}$, 对应于西峰黄土.

渐新世以来季风加强导致硅酸盐风化引起的长期 $\mathrm{CO}_{2}$ 消耗 $\left(F_{\text {sil }}\right)$ 变化范围在 $0.18 \times 10^{12} \sim 0.73 \times 10^{12} \mathrm{~mol} \mathrm{a}^{-1}$ (Clift模型)或者 $0.06 \times 10^{12} \sim 0.87 \times 10^{12} \mathrm{~mol} \mathrm{a}^{-1}$ (Métivier模 型)(图7d). 方程(1)中计算的长期 $\mathrm{CO}_{2}$ 消耗， $\mathrm{Na}-\mathrm{K}$ 硅酸 盐风化仅占次要地位. 因此本文计算的硅酸盐风化引 起的长期 $\mathrm{CO}_{2}$ 消耗不能直接和现代全球大陆硅酸盐风 化引起的 $\mathrm{CO}_{2}$ 消耗 $\left(7.85 \times 10^{12} \sim 8.7 \times 10^{12} \mathrm{~mol} \mathrm{a}^{-1}\right.$, Gaillardet等, 1999; Moon等, 2014)直接对比. 首先, 这是因为 现代全球大陆硅酸盐风化引起的 $\mathrm{CO}_{2}$ 消耗包含了 $\mathrm{Ca}$ 、

$\mathrm{Na} 、 \mathrm{~K}$ 和 $\mathrm{Mg}$ 硅酸盐风化的总贡献，而其中 $\mathrm{Ca}$ 和 $\mathrm{Mg}$ 硅 酸盐贡献约占60\%(Gaillardet等, 1999; Moon等, 2014). 必须注意的是，由于本文 $\left(\Delta \mathrm{Mg}_{0}+\Delta \mathrm{Ca}_{0}\right)$ 对 $C_{\text {sil }}$ 贡献平均 高达 $88 \%$ (图5a), 计算得到的 $F_{\text {sil }}$ 中平均约 $86 \%$ 的贡献 来自 $\mathrm{Ca}$ 和 $\mathrm{Mg}$ 硅酸盐风化. 其次, 如果在近现代时间尺 度上 $2 \mathrm{~mol}$ 大气 $\mathrm{CO}_{2}$ 在 $1 \mathrm{~mol}$ 的 $\mathrm{Ca}$ 或者 $\mathrm{Mg}$ 硅酸盐风化中 消耗, 产生的 $2 \mathrm{~mol}$ 的 $\mathrm{HCO}_{3}^{-}$在海洋中以碳酸盐形式沉淀 时将会释放 $1 \mathrm{~mol}$ 的 $\mathrm{CO}_{2}$ 重新返回大气, 因此在地质时 间尺度仅有 $1 \mathrm{~mol}$ 的 $\mathrm{CO}_{2}$ 最终通过硅酸盐风化被埋藏. 基于此，本文用 $F_{\mathrm{sil}}$ 中的 $\mathrm{Ca}$ 和 $\mathrm{Mg}$ 贡献来对比现代全球 大陆 $\mathrm{Ca}$ 和 $\mathrm{Mg}$ 硅酸盐风化速率 $\left(2.17 \times 10^{12} \sim 2.5 \times 10^{12}\right.$ mol a ${ }^{-1}$, Gaillardet等, 1999; Moon等, 2014). 在这种情 况下，本文分析的晚渐新世以来 $F_{\mathrm{sil}}$ 中 $\mathrm{Ca}$ 和 $\mathrm{Mg}$ 硅酸盐 贡献部分占全球大陆 $\mathrm{Ca}$ 和 $\mathrm{Mg}$ 硅酸盐风化的 6 29\% (Clift模型)或2 35\%(Métivier模型); 其中晚渐新世时期 $\mathrm{Ca}$ 和 $\mathrm{Mg}$ 硅酸盐风化占全球大陆 $\mathrm{Ca}$ 和 $\mathrm{Mg}$ 硅酸盐风化速 率的11 16\%(Clift模型)或2 4\%(Métivier模型).

季风加强导致有机碳埋藏引起的长期 $\mathrm{CO}_{2}$ 消耗 $\left(F_{\text {oc }}\right)$ 可表示为 

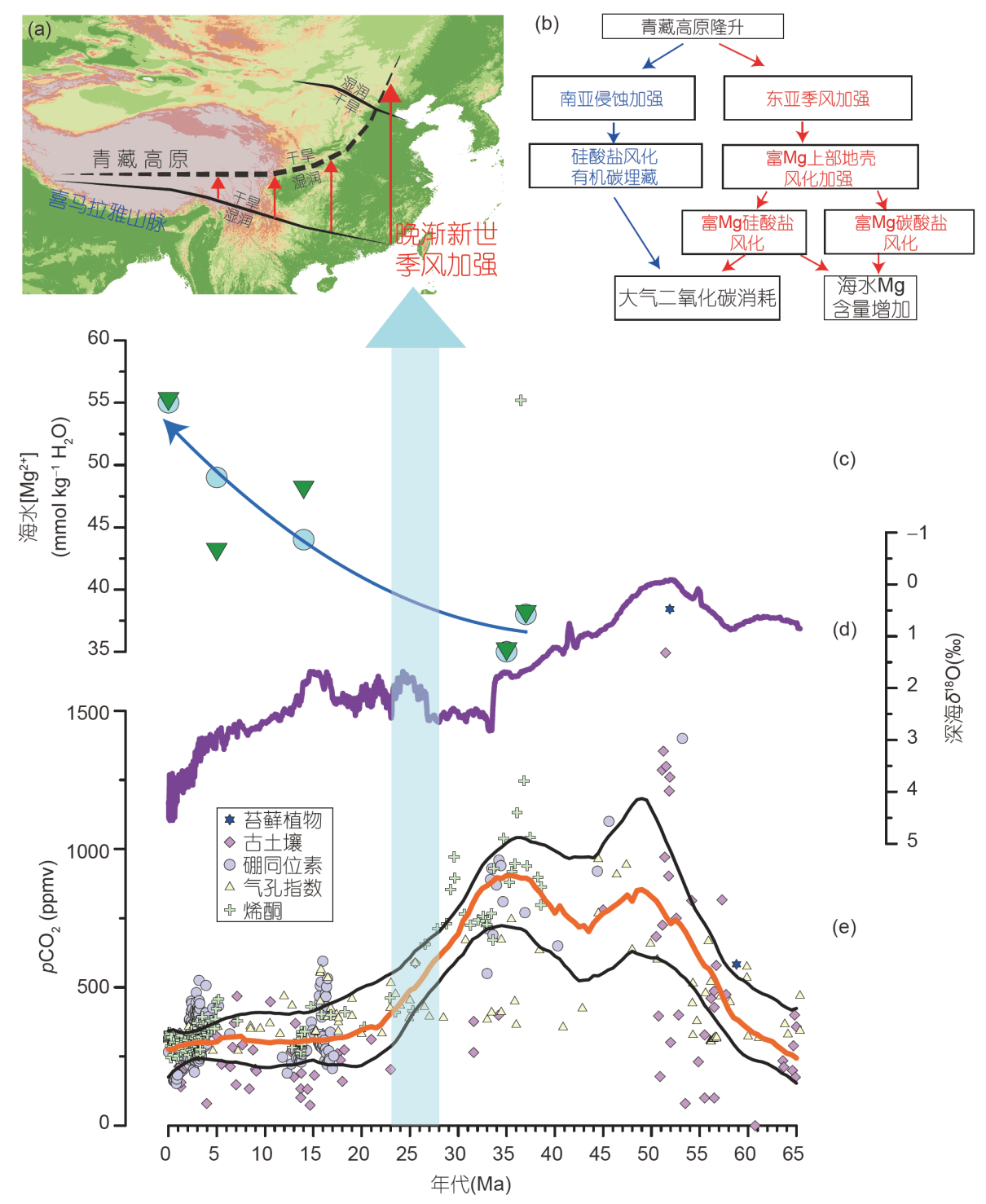

图 8 晚渐新世东亚季风加强及其对全球影响的示意图

(b)中的蓝色字体和箭头表示南亚山脉隆升(喜马拉雅山脉)消耗大气 $\mathrm{CO}_{2}$ 的传统观点(Raymo等, 1988; France-Lanord和Derry, 1997); 而红色字 体和箭头表示本文提出的东亚季风加强消耗大气 $\mathrm{CO}_{2}$ 的观点. (c)基于海相石盐原生包裹体的海水 $\mathrm{Mg}^{2+}$ 含量重建(绿色三角形, Horita等, 2002; 蓝色圆圈, Zimmermann, 2000). (d)新生代深海氧同位素(Zachos等, 2008). (e)新生代大气 $\mathrm{CO}_{2}$ 含量重建(基于各种分析的平均值/中值)以及这些 数据的LOESS拟合(橙色粗线, LOESS拟合; 黑线, 95\%置信区间)(Foster等, 2017)

$F_{\mathrm{oc}}=E_{\mathrm{a}} \times M_{\mathrm{a}} \times f_{\mathrm{a}}-E_{\mathrm{b}} \times M_{\mathrm{b}} \times f_{\mathrm{b}}$.

基于两种沉积通量模型重建的 $F_{\mathrm{oc}}$ 始终小于全球有机 碳通量的 $3.5 \%$ (图7e). 有机碳埋藏消耗的 $\mathrm{CO}_{2}$ 通量约为 同时期硅酸盐风化引起的 $\mathrm{CO}_{2}$ 消耗通量的四分之一. 这种现象与喜马拉雅地区相反, 那里有机碳埋藏对长 期 $\mathrm{CO}_{2}$ 消耗的贡献远大于硅酸盐风化(France-Lanord和 Derry, 1997).

尽管本文重建的硅酸盐风化和有机碳埋藏引起的
长期 $\mathrm{CO}_{2}$ 消耗随时间变化很大, 但是二者之和 $\left(F_{\mathrm{sil}}+F_{\mathrm{oc}}\right)$ 大致与喜马拉雅地区碳消耗 $\left(1.28 \times 10^{12} \mathrm{~mol} \mathrm{a}^{-1}\right.$, FranceLanord和Derry, 1997)处于相同数量级. 如果新生代全 球长期硅酸盐风化通量是相对稳定的(Caves等, 2016), 本文重建的中国东部硅酸盐风化和有机碳埋藏引起的 长期 $\mathrm{CO}_{2}$ 消耗足以导致地质碳循环的失衡. 其中, $\mathrm{Mg}$ 硅酸盐亏损 $(\Delta \mathrm{Mg})$ 占了硅酸盐 $\mathrm{CO}_{2}$ 消耗 $\left(\Delta_{\mathrm{sil}}\right)$ 的 $58 \sim 65 \%$, 平均值为 $62 \%$ (网络版附表 3 ); 而 $\mathrm{Mg}$ 硅酸盐的 $\mathrm{CO}_{2}$ 消耗 
通量 $\left(F_{\mathrm{Mg}, \text { sil }}\right)$ 占了硅酸盐 $\mathrm{CO}_{2}$ 消耗通量 $\left(F_{\mathrm{sil}}\right)$ 的 $50 \sim 55 \%$ (图7). 考虑到研究区只占约 $2 \%$ 的地球陆地面积, 晚渐 新世以来中国东部富 $\mathrm{Mg}$ 上地壳在湿润季风气候条件 下风化增强提供了显著的新生碳汇。中国亚热带地区 富 $\mathrm{Mg}$ 上地壳在湿润气候下的风化也对全球变冷所需 的陆表反应度(land surface reactivity)增加作出贡献(如 Kump和Arthur, 1997; Caves等, 2016; Caves Rugenstein 等, 2019). 另外, 季风加强之后湿润的中国亚热带地区 富白云石碳酸盐的风化也可能通过水生生物光合作用 成为长期碳汇(如Liu等, 2018).

\section{5 启示和结论}

本文的气候模拟结果显示随着青藏高原北部隆 升, 中国东部的年均降水量显著增加了约 100 $>400 \mathrm{~mm}$ (图4c). 而且, 大部分年均降水量的增加发生 在夏季, 且集中在华北和扬子克拉通所围限的区域(图 4d). 在夏季, 地形抬升加热导致亚洲低压增强, 中国东 部盛行异常强盛的东南风和/或西南风(图4d). 因此, 模 拟结果指示了东亚夏季风环流在该区域开始出现或者 比以往大大增强. 这表明东亚季风在中国东部的形成 或强化与青藏高原北部隆升存在紧密的构造-气候关 联(如Tada等, 2016; Zhang等, 2017). 尽管副特提斯海 和全球变冷及其他因素可能是始新世/渐新世转型后 亚洲内陆干旱和季风加强的潜在影响因素(Zhang等, 2007a, 2007b, 2018; Zoura等, 2019), 但青藏高原地形 改变被证明是亚洲水文气候变化的主要驱动力(Zoura 等，2019). 众多的构造变形、剥露过程和火山岩侵位 证据证明青藏高原, 特别是青藏高原北部, 晚渐新世早中新世存在快速隆升并伴随一系列构造活动事件 (Lu等, 2018及其参考文献; Fang等, 2020; Li等, 2021; Yang等, 2021a). 因此, 印度-亚洲板块碰撞对碰撞带以 外东亚地区产生巨大的环境效应，驱动了东亚季风深 入到构造相对欠活跃的中国东部亚热带地区使得东亚 气候格局重组, 并通过加强风化作用影响了全球碳和 镁循环(图8a、8b).

有关新生代造山运动通过消耗大气 $\mathrm{CO}_{2}$ 影响全球 气候的研究几乎都只关注印度-亚洲板块碰撞带(图 8a、8b; Raymo等, 1988; France-Lanord和Derry, 1997). 而本研究揭示了印度-亚洲板块碰撞和青藏高原隆升 也可以通过改变东亚地区气候来显著增强大气 $\mathrm{CO}_{2}$ 消 耗(图8b). 印度-亚洲板块碰撞和青藏高原隆升在南亚 通过加强硅酸盐风化和有机碳埋藏消耗大气 $\mathrm{CO}_{2}$, 可 视为该造山运动影响全球碳循环的直接途径. 而青藏 高原隆升通过加强扬子克拉通及其周围地块的富 $\mathrm{Mg}$ 硅酸盐风化也可以大量消耗大气 $\mathrm{CO}_{2}$; 并且由于其消 耗量与发生在南亚的大气 $\mathrm{CO}_{2}$ 消耗在数量级上几乎 相等, 因此可视为该造山运动影响全球碳循环的间接 途径. 中国东部上地壳暴露物质的富 $\mathrm{Mg}$ 独特性暗示 了构造运动通过改变地质碳循环影响新生代变冷的 方式是多样的，而且这种影响机制尚未在更老的全球 造山运动研究中被充分认识. 本研究因此描绘了造山 带隆升对全球气候和大气 $\mathrm{CO}_{2}$ 含量影响的复杂方式: 不仅强调了直接参与碰撞过程的地壳属性的重要性, 而且强调了碰撞带周围地壳属性的重要性. 这种碰撞 带周围地壳属性的重要性(中国东部富 $\mathrm{Mg}$ 上地壳)体 现在，尽管它没有参与到碰撞过程中来，但是它对气 候反馈敏感, 从而可以引起全球碳循环失衡. 尽管气 候触发的中国东部有机碳埋藏引起的大气 $\mathrm{CO}_{2}$ 消耗 变化量较小, 但是气候触发的富 $\mathrm{Mg}$ 上地壳风化增强 可能促进了晚渐新世大气 $\mathrm{CO}_{2}$ 含量的快速下降(图8e; Beerling和Royer, 2011; Foster等, 2017). 这种铁镁质 岩石对于加剧化学风化和碳消耗的有效性也被其他 研究所证明, 如东南亚岛屿的出现可能驱动了新近纪 变冷(Park等, 2020), 以及晚中新世东亚季风增强可能 驱动了约 $7 \mathrm{Ma}$ 开始的全球快速降温(Yang等, 2021b). 此外, 中国东部富 $\mathrm{Mg}$ 上地壳暴露在强风化环境可以 增加陆表反应度从而调控新近纪全球变冷(Caves Rugenstein等, 2019), 也可以通过河流输送大量Mg进入 海洋影响全球 $\mathrm{Mg}$ 循环(图8b). 本研究提供了复杂构 造-气候作用下青藏高原隆升对于全球碳和镁循环的 定量近似分析, 但依然存在很多未解决的不确定性留 待未来研究, 如在短期和长期时间尺度上中国东部侵 蚀速率的变化及差异(Métivier和Gaudemer， 1999; Clift，2006) 以及土壤数据空间上的不均一性及时间 上的变率等.

致谢气候模拟在国家超级计算广州中心天河二号上完 成. Lee Kump对论文早期版本提供了建设性意见，金章 东、李高军、张飞、汪进和宋博文在成文过程中与作者 开展了有益的讨论并提供了宝贵意见和帮助, 三位若名 审稿人给予了详细指导意见, 在此一并谨致谢忱. 


\section{参考文献}

湖北省地质矿产局. 1996. 湖北省岩石地层. 武汉: 中国地质大学出 版社. 1-284

马小林. 2012. 李官桥盆地中始新世磁性地层及中国古近纪植被-气 候时空演化研究. 硕士学位论文. 北京: 中国地质大学(北京). 158

钱勤, 李坤英. 1996. 苏北盆地玄武岩地质年龄及地层时代. 火山地 质与矿产, 17: 86-93

申琪. 2018. 四川盆地西南缘白严纪一新生代磁性地层及其地质意 义. 硕士学位论文. 西安: 西北大学. 1-69

宋博文, 张克信, 徐亚东, 侯亚飞, 季军良, 骆满生. 2020. 中国古近纪 构造-地层区划及地层格架. 地球科学, 45: 4352-4369

孙文峰, 鹿化煜, 王逸超, 冯晗, 王翰林, 李永祥, 吴耕泓, 李姝玥, 蒋 品欣. 2017. 渭河盆地蓝田始新世红河组沉积物特征和古环境记 录. 高校地质学报, 3: 533-544

张建新, 鲁江, 邢旭东, 申志军, 吕焕哲, 张国梁. 2007. 湖南洞庭湖地 区红土的元素地球化学特征及其指示意义. 地质通报, 26: 14351444

中国环境监测总站. 1990. 中国土壤元素背景值. 北京: 中国环境科 学出版社

Beerling D J, Royer D L. 2011. Convergent Cenozoic $\mathrm{CO}_{2}$ history. Nat Geosci, 4: 418-420

Blair N E, Aller R C. 2012. The fate of terrestrial organic carbon in the marine environment. Annu Rev Mar Sci, 4: 401-423

Blum J D, Gazis C A, Jacobson A D, Page Chamberlain C. 1998 Carbonate versus silicate weathering in the Raikhot watershed within the High Himalayan Crystalline Series. Geology, 26: 411414

Caves J K, Jost A B, Lau K V, Maher K. 2016. Cenozoic carbon cycle imbalances and a variable weathering feedback. Earth Planet Sci Lett, 450: 152-163

Caves Rugenstein J K, Ibarra D E, von Blanckenburg F. 2019. Neogene cooling driven by land surface reactivity rather than increased weathering fluxes. Nature, 571: 99-102

Chappell J, Zheng H, Fifield K. 2006. Yangtse River sediments and erosion rates from source to sink traced with cosmogenic ${ }^{10} \mathrm{Be}$ : Sediments from major rivers. Palaeogeogr Palaeoclimatol Palaeoecol, 241: 79-94

Clift P D. 2006. Controls on the erosion of Cenozoic Asia and the flux of clastic sediment to the ocean. Earth Planet Sci Lett, 241: 571-580

Clift P D, Layne G D, Blusztajn J. 2004. Marine sedimentary evidence for monsoon strengthening, Tibetan uplift and drainage evolution in East Asia. In: Clift P, Wang P, Kuhnt W, Hayes D E, eds. ContinentOcean Interactions Within the East Asian Marginal Seas. American Geophysical Union. 255-282
Coggon R M, Teagle D A H, Smith-Duque C E, Alt J C, Cooper M J. 2010. Reconstructing past seawater $\mathrm{Mg} / \mathrm{Ca}$ and $\mathrm{Sr} / \mathrm{Ca}$ from midocean ridge flank calcium carbonate veins. Science, 327: 1114-1117

Condie K C. 1993. Chemical composition and evolution of the upper continental crust: Contrasting results from surface samples and shales. Chem Geol, 104: 1-37

Dai S, Fang X, Song C. 2005. Early tectonic uplift of the northern Tibetan Plateau. Chin Sci Bull, 50: 1642-1652

Dunlea A G, Murray R W, Santiago Ramos D P, Higgins J A. 2017. Cenozoic global cooling and increased seawater $\mathrm{Mg} / \mathrm{Ca}$ via reduced reverse weathering. Nat Commun, 8: 1-7

Fan L G, Meng Q R, Wu G L, Wei H H, Du Z M, Wang E. 2019. Paleogene crustal extension in the eastern segment of the NE Tibetan plateau. Earth Planet Sci Lett, 514: 62-74

Fang X, Galy A, Yang Y, Zhang W, Ye C, Song C. 2019. Paleogene global cooling-induced temperature feedback on chemical weathering, as recorded in the northern Tibetan Plateau. Geology, 47: 992-996

Fang X, Dupont-Nivet G, Wang C, Song C, Meng Q, Zhang W, Nie J, Zhang T, Mao Z, Chen Y. 2020. Revised chronology of central Tibet uplift (Lunpola Basin). Sci Adv, 6: eaba7298

Foster G L, Royer D L, Lunt D J. 2017. Future climate forcing potentially without precedent in the last 420 million years. Nat Commun, 8: 14845

France-Lanord C, Derry L A. 1997. Organic carbon burial forcing of the carbon cycle from Himalayan erosion. Nature, 390: 65-67

Gaillardet J, Dupré B, Louvat P, Allègre C J. 1999. Global silicate weathering and $\mathrm{CO}_{2}$ consumption rates deduced from the chemistry of large rivers. Chem Geol, 159: 3-30

Gallet S, Jahn B, Torii M. 1996. Geochemical characterization of the Luochuan loess-paleosol sequence, China, and paleoclimatic implications. Chem Geol, 133: 67-88

Galy V, France-Lanord C, Beyssac O, Faure P, Kudrass H, Palhol F. 2007. Efficient organic carbon burial in the Bengal fan sustained by the Himalayan erosional system. Nature, 450: 407-410

Gao S, Zhang B, Xie Q, Gu X, Ouyang J, Wang D, Gao C. 1991. Average chemical compositions of post-Archean sedimentary and volcanic rocks from the Qinling Orogenic Belt and its adjacent North China and Yangtze Cratons. Chem Geol, 92: 261-282

Gao S, Luo T C, Zhang B R, Zhang H F, Han Y, Zhao Z D, Hu Y K. 1998. Chemical composition of the continental crust as revealed by studies in East China. Geochim Cosmochim Acta, 62: 1959-1975

Guo Z T, Sun B, Zhang Z S, Peng S Z, Xiao G Q, Ge J Y, Hao Q Z, Qiao Y S, Liang M Y, Liu J F, Yin Q Z, Wei J J. 2008. A major reorganization of Asian climate by the early Miocene. Clim Past, 4: 153-174 
He Z, Zhang M, Wilson M J. 2004. Distribution and classification of red soils in China. In: Wilson M J, He Z, Yang X, eds. The Red Soils of China. Dordrecht: Springer. 29-33

He M, Zheng H, Clift P D, Tada R, Wu W, Luo C. 2015. Geochemistry of fine-grained sediments in the Yangtze River and the implications for provenance and chemical weathering in East Asia. Prog Earth Planet Sci, 2: 32

Hilton R G, Galy A, Hovius N, Horng M J, Chen H. 2011. Efficient transport of fossil organic carbon to the ocean by steep mountain rivers: An orogenic carbon sequestration mechanism. Geology, 39: $71-74$

Higgins J A, Schrag D P. 2015. The Mg isotopic composition of Cenozoic seawater-evidence for a link between Mg-clays, seawater $\mathrm{Mg} / \mathrm{Ca}$, and climate. Earth Planet Sci Lett, 416: 73-81

Hong H, Wang C, Zeng K, Gu Y, Wu Y, Yin K, Li Z. 2013 Geochemical constraints on provenance of the mid-Pleistocene red earth sediments in subtropical China. Sediment Geol, 290: 97-108

Horita J, Zimmermann H, Holland H D. 2002. Chemical evolution of seawater during the Phanerozoic: Implications from the record of marine evaporites. Geochim Cosmochim Acta, 66: 3733-3756

Huang C, Hinnov L. 2019. Astronomically forced climate evolution in a saline lake record of the middle Eocene to Oligocene, Jianghan Basin, China. Earth Planet Sci Lett, 528: 115846

Kump L R, Arthur M A. 1997. Global chemical erosion during the Cenozoic: Weatherability balances the budgets. In: Ruddiman W F, ed. Tectonic Uplift and Climate Change. New York: Plenum Press. 399-426

Lee H, Galy V, Feng X, Ponton C, Galy A, France-Lanord C, Feakins S J. 2019. Sustained wood burial in the Bengal Fan over the last 19 My. Proc Natl Acad Sci USA, 116: 22518-22525

Li G, Elderfield H. 2013. Evolution of carbon cycle over the past 100 million years. Geochim Cosmochim Acta, 103: 11-25

Li C, Zheng D, Zhou R, Yu J, Wang Y, Pang J, Wang Y, Hao Y, Li Y. 2021. Late Oligocene tectonic uplift of the East Kunlun Shan: Expansion of the northeastern Tibetan Plateau. Geophys Res Lett, 48: e91281

Liang M, Guo Z, Kahmann A J, Oldfield F. 2009. Geochemical characteristics of the Miocene eolian deposits in China: Their provenance and climate implications. Geochem Geophys Geosyst, 10: Q04004

Licht A, van Cappelle M, Abels H A, Ladant J B, Trabucho-Alexandre J, France-Lanord C, Donnadieu Y, Vandenberghe J, Rigaudier T, Lécuyer C, Terry Jr D, Adriaens R, Boura A, Guo Z, Soe A N, Quade J, Dupont-Nivet G, Jaeger J J. 2014. Asian monsoons in a late Eocene greenhouse world. Nature, 513: 501-506

Lin J, Dai J G, Zhuang G, Jia G, Zhang L, Ning Z, Li Y, Wang C. 2020.
Late Eocene-Oligocene high relief paleotopography in the North Central Tibetan Plateau: Insights from detrital zircon U-Pb geochronology and leaf wax hydrogen isotope studies. Tectonics, 39: e 05815

Liu X, Sun H, Miao Y, Dong B, Yin Z Y. 2015. Impacts of uplift of northern Tibetan Plateau and formation of Asian inland deserts on regional climate and environment. Quat Sci Rev, 116: 1-14

Liu Z, Trentesaux A, Clemens S C, Colin C, Wang P, Huang B, Boulay S. 2003. Clay mineral assemblages in the northern South China Sea: Implications for East Asian monsoon evolution over the past 2 million years. Mar Geol, 201: 133-146

Liu Z, Macpherson G L, Groves C, Martin J B, Yuan D, Zeng S. 2018. Large and active $\mathrm{CO}_{2}$ uptake by coupled carbonate weathering. Earth-Sci Rev, 182: 42-49

Lu H, Tian X, Yun K, Li H. 2018. Convective removal of the Tibetan Plateau mantle lithosphere by $\sim 26$ Ma. Tectonophysics, 731-732: $17-34$

Maher K, Chamberlain C P. 2014. Hydrologic regulation of chemical weathering and the geologic carbon cycle. Science, 343: 1502-1504

Métivier F, Gaudemer Y. 1999. Stability of output fluxes of large rivers in South and East Asia during the last 2 million years: Implications on floodplain processes. Basin Res, 11: 293-303

Métivier F, Gaudemer Y, Tapponnier P, Klein M. 1999. Mass accumulation rates in Asia during the Cenozoic. Geophys J Int, 137: $280-318$

Meng X, Liu L, Balsam W, Li S, He T, Chen J, Ji J. 2015. Dolomite abundance in Chinese loess deposits: A new proxy of monsoon precipitation intensity. Geophys Res Lett, 42: 10,391

Miao Y, Wu F, Herrmann M, Yan X, Meng Q. 2013. Late early Oligocene East Asian summer monsoon in the NE Tibetan Plateau: Evidence from a palynological record from the Lanzhou Basin, China. J Asian Earth Sci, 75: 46-57

Milliman J D, Syvitski J P M. 1992. Geomorphic/tectonic control of sediment discharge to the ocean: The importance of small mountainous rivers. J Geol, 100: 525-544

Moon S, Chamberlain C P, Hilley G E. 2014. New estimates of silicate weathering rates and their uncertainties in global rivers. Geochim Cosmochim Acta, 134: 257-274

Park Y, Maffre P, Goddéris Y, Macdonald F A, Anttila E S C, Swanson-Hysell N L. 2020. Emergence of the Southeast Asian islands as a driver for Neogene cooling. Proc Natl Acad Sci USA, 117: $25319-25326$

Raymo M E, Ruddiman W F, Froelich P N. 1988. Influence of late Cenozoic mountain building on ocean geochemical cycles. Geology, 16: 649-653

Raymo M E, Ruddiman W F. 1992. Tectonic forcing of late Cenozoic 
climate. Nature, 359: 117-122

Ren J, Niu B, Wang J, Jin X, Zhao L, Liu R. 2013. Advances in research of Asian geology - A summary of 1:5 M international geological map of Asia project. J Asian Earth Sci, 72: 3-11

Rudnick R L, Gao S. 2004. Composition of the continental crust. Treat Geochem, 3: 1-65

Scotese C R. 2004. Atlas of Paleogene Paleogeographic Maps (Mollweide Projection), Maps 8-15, Volume 1, The Cenozoic. PALEOMAP Atlas for ArcGIS, PALEOMAP Project, Evanston, IL Shaw D M, Reilly G A, Muysson J R, Pattenden G E, Campbell F E. 1967. An estimate of the chemical composition of the Canadian Precambrian shield. Can J Earth Sci, 4: 829-853

Shipboard Scientific Party, Site 1146. 2000. In: Wang P, Prell W L, Blum P, et al., eds., Proc ODP Init Rep. 184

Song B, Spicer R A, Zhang K, Ji J, Farnsworth A, Hughes A C, Yang Y, Han F, Xu Y, Spicer T, Shen T, Lunt D J, Shi G. 2020. Qaidam Basin leaf fossils show northeastern Tibet was high, wet and cool in the early Oligocene. Earth Planet Sci Lett, 537: 116175

Spicer R A, Yang J, Herman A B, Kodrul T, Maslova N, Spicer T E V, Aleksandrova G, Jin J. 2016. Asian Eocene monsoons as revealed by leaf architectural signatures. Earth Planet Sci Lett, 449: 61-68

Sun X, Wang P. 2005. How old is the Asian monsoon system?Palaeobotanical records from China. Palaeogeogr Palaeoclimatol Palaeoecol, 222: 181-222

Tada R, Zheng H, Clift P D. 2016. Evolution and variability of the Asian monsoon and its potential linkage with uplift of the Himalaya and Tibetan Plateau. Prog Earth Planet Sci, 3: 4

Tapponnier P, Zhiqin X, Roger F, Meyer B, Arnaud N, Wittlinger G, Jingsui Y. 2001. Oblique stepwise rise and growth of the Tibet Plateau. Science, 294: 1671-1677

Taylor S R, McLennan S M. 1985. The Continental Crust: Its Composition and Evolution. Oxford: Blackwell Scientific Publications

Teng X, Fang X, Kaufman A J, Liu C, Wang J, Zan J, Yang Y, Wang C,

Xu H, Schulte R F, Piatak N M. 2019. Sedimentological and mineralogical records from drill core SKD1 in the Jianghan Basin, Central China, and their implications for late Cretaceous-early Eocene climate change. J Asian Earth Sci, 182: 103936

Wan S, Clift P D, Li A, Li T, Yin X. 2010. Geochemical records in the South China Sea: Implications for East Asian summer monsoon evolution over the last $20 \mathrm{Ma}$. Geol Soc Lond Spec Publ, 342: 245263

West A J, Galy A, Bickle M. 2005. Tectonic and climatic controls on silicate weathering. Earth Planet Sci Lett, 235: 211-228

Wieder W R, Boehnert J, Bonan G B, Langseth M. 2014. Regridded Harmonized World Soil Database v1.2. Data set. Available online [http://daac.ornl.gov] from Oak Ridge National Laboratory Distributed Active Archive Center, Oak Ridge, Tennessee, USA

Xie Y, Wu F, Fang X. 2020a. A major environmental shift by the middle Eocene in southern China: Evidence from palynological records. Rev Palaeobot Palynol, 278: 104226

Xie Y, Wu F, Fang X, Zhang D, Zhang W. 2020b. Early Eocene southern China dominated by desert: Evidence from a palynological record of the Hengyang Basin, Hunan Province. Glob Planet Change, 195: 103320

Xiong S, Ding Z, Zhu Y, Zhou R, Lu H. 2010. A 6 Ma chemical weathering history, the grain size dependence of chemical weathering intensity, and its implications for provenance change of the Chinese loess-red clay deposit. Quat Sci Rev, 29: 1911-1922

Xiong Z, Ding L, Spicer R A, Farnsworth A, Wang X, Valdes P J, Su T, Zhang Q, Zhang L, Cai F, Wang H, Li Z, Song P, Guo X, Yue Y. 2020. The early Eocene rise of the Gonjo Basin, SE Tibet: From low desert to high forest. Earth Planet Sci Lett, 543: 116312

Yang S, Ding F, Ding Z. 2006. Pleistocene chemical weathering history of Asian arid and semi-arid regions recorded in loess deposits of China and Tajikistan. Geochim Cosmochim Acta, 70: 1695-1709

Yang Y, Galy A, Fang X, Yang R, Zhang W, Song B, Liu Y, Han W, Zhang W, Yang S. 2021a. Neodymium isotopic constraints on Cenozoic Asian dust provenance changes linked to the exhumation history of the northern Tibetan Plateau and the Central Asian Orogenic Belt. Geochim Cosmochim Acta, 296: 38-55

Yang Y, Ye C, Galy A, Fang X, Xue Y, Liu Y, Yang R, Zhang R, Han W, Zhang W, Ruan X. 2021b. Monsoon-enhanced silicate weathering as a new atmospheric $\mathrm{CO}_{2}$ consumption mechanism contributing to fast late Miocene global cooling. Paleoceanogr Paleoclimatol, 36: e2020PA004008

Zachos J C, Dickens G R, Zeebe R E. 2008. An early Cenozoic perspective on greenhouse warming and carbon-cycle dynamics. Nature, 451: 279-283

Zhang J, Liu Y, Fang X, Wang C, Yang Y. 2019. Large dry-humid fluctuations in Asia during the Late Cretaceous due to orbital forcing: A modeling study. Palaeogeogr Palaeoclimatol Palaeoecol, 533: 109230

Zhang R, Jiang D, Zhang Z, Cheng Z, Zhang Q. 2017. Comparison of the climate effects of surface uplifts from the northern Tibetan Plateau, the Tianshan, and the Mongolian Plateau on the East Asian climate. J Geophys Res-Atmos, 122: 7949-7970

Zhang R, Zhang Z, Jiang D. 2018. Global cooling contributed to the establishment of a modern-like East Asian Monsoon climate by the early Miocene. Geophys Res Lett, 45: 11,941

Zhang Y G, Pagani M, Liu Z, Bohaty S M, Deconto R. 2013. A 40million-year history of atmospheric $\mathrm{CO}_{2}$. Phil Trans R Soc A, 371: 
20130096

Zhang Z, Wang H, Guo Z, Jiang D. 2007a. What triggers the transition of palaeoenvironmental patterns in China, the Tibetan Plateau uplift or the Paratethys Sea retreat? Palaeogeogr Palaeoclimatol Palaeoecol, 245: 317-331

Zhang Z, Wang H, Guo Z, Jiang D. 2007b. Impacts of tectonic changes on the reorganization of the Cenozoic paleoclimatic patterns in China. Earth Planet Sci Lett, 257: 622-634
Zheng Y F, Xiao W J, Zhao G. 2013. Introduction to tectonics of China. Gondwana Res, 23: 1189-1206

Zimmermann H. 2000. Tertiary seawater chemistry; implications from primary fluid inclusions in marine halite. Am J Sci, 300: 723-767

Zoura D, Hill D J, Dolan A M, Hunter S J, Tang Z, Haywood A M. 2019. Atmospheric carbon dioxide, ice sheet and topographic constraints on palaeo moisture availability in Asia. Earth Planet Sci Lett, 519: 12-27

(责任编委: 翦知淐) 